\title{
UNA APROXIMACIÓN A LA IDEA DE CULTURA CONSTITUCIONAL*
}

\author{
AN APPROACH TO THE CONSTITUTIONAL CULTURE IDEA
}

\author{
Ignacio Álvarez Rodríguez**
}

\begin{abstract}
RESUMEN: La investigación que aquí se presenta es una reflexión en torno a la idea de cultura constitucional. Para ello se parte primero de una serie de conceptos constitucionales basilares, para posteriormente desgranar cuál es el concepto y caracteres de la noción, sus principales desarrollos para posteriormente fijar la vista en España y su peculiar idiosincrasia constitucional, de ayer, hoy y siempre.
\end{abstract}

ABSTRACT: The research shows a reflection on the constitutional culture topic. To that extent, firstly we introduce well-known core constitutional principles and then expose the notion and implementation of the issue given. Finally, we try to shed light to the Spanish case, with a very particular constitutional frame.

PALABRAS CLAVE: constitución, cultura constitucional, constitucionalismo.

KEYWORDS: constitution, constitutional culture, constitutionalism.

Fecha de recepción: 27/10/2020

Fecha de aceptación: 18/11/2020

doi: https://doi.org/10.20318/universitas.2020.5872

* El trabajo se ha realizado en el marco del Proyecto DER2016-75993-P, sobre España ante Europa: retos nacionales en materia de derechos humanos, 30 de diciembre de 2016 - 29 de diciembre 2020 (IP: Francisco Javier Matia Portilla).

** Profesor ayudante-doctor de Derecho Constitucional por la Universidad Complutense de Madrid. E-mail: ialvarez1@ucm.es 


\section{1.- Planteamiento}

En el presente texto vamos a intentar esbozar algunas ideas sobre la cultura constitucional. Para ello debemos hacer en primer término una introducción a dicho concepto que repase cuestiones básicas como el concepto de Constitución, las formas de clasificarlas, y su procedimiento de elaboración y modificación. Una vez hayamos aclarado los términos del debate nos adentraremos en la definición y caracteres de la cultura constitucional, así como en los tipos de cultura constitucional existentes, para finalizar con un breve repaso a la idea de cultura constitucional en España, muy marcada por nuestra particular Historia (constitucional y no constitucional), que abrocharemos con una reflexión final a modo de colofón.

\section{2.- INTRODUCIENDO LA CULTURA CONSTITUCIONAL}

En el presente apartado presentaremos los términos del debate, tarea necesaria en la medida en que será el objeto sobre lo que debemos tener una "cultura.

\section{1.- Concepto de Constitución}

La noción de Constitución puede entenderse, jurídicamente hablando, en dos sentidos: en sentido descriptivo y en sentido prescriptivo (normativo). ${ }^{1}$ La Constitución en sentido descriptivo se refiere al ser. Así, la Constitución es el conjunto de normas supremas de un ordenamiento jurídico que sirven de fundamento de validez al resto de normas. El principal problema que plantea esta concepción es que nada dice sobre el contenido material de esa Constitución (lógica y obviamente, por otro lado). La Constitución en sentido prescriptivo (normativo) se refiere al deber ser. De ese modo, la Constitución debe articularse de tal forma que asegure la libertad política y limite la acumulación del poder. Toda Constitución que se precie debe materializar el artículo 16 de la Declaración Universal de los Derechos del Hombre y del Ciudadano de 1789: garantizar los derechos fundamentales y establecer la separación de poderes.

Mucho se ha discutido sobre ambas nociones y sobre el origen de la aparición de la palabra "Constitución". ¿Se refiere a la primera o a la segunda? Lo cierto y verdad es que la primera tiene un fuerte componente de Derecho Romano, aunque "constitutio" es diferente,

\footnotetext{
1 Respecto a la Constitución de 1978 desde nuestro constitucionalismo son imprescindibles las obras de DÍEZ-PICAZO, L.Ma; Ordenamiento constitucional español, Tirant lo Blanch, Valencia, 2020; LÓPEZ GUERRA, L; La Constitución de España, Tirant lo Blanch, Valencia, 2019; y DÍEZ-PICAZO, L.Ma; y ELVIRA PERALES, A; La Constitución de 1978, Iustel, Madrid, 2008. Un balance no menos imprescindible de estos cuarenta años de Estado constitucional se puede leer en BLANCO VALDÉS, R; Luz tras las tinieblas. Vindicación de la España constitucional, Alianza, Madrid, 2018.
} 
dado que se identifica con el mandato del soberano. Posteriormente cambia, en los siglos XVI y XVII, para referirse a la misma. Según la mejor Ciencia Política la noción de Constitución se vincula necesariamente a la de constitucionalismo. Es decir, la Constitución real y verdadera es una norma fundamental que no sólo es una norma fundamental, sino que debe asegurar y defender los postulados liberales, por la sencilla razón de que será el liberalismo quien cree dicha Constitución. En la Francia del Antiguo Régimen ya se empleaba la palabra "Constitución" en términos parecidos a los actuales (por ejemplo, en las Constituciones del Reino, donde el rey no podía hacer según qué cosas, la idea de limitar el poder estaba firmemente asentada). ${ }^{2}$

Lo que resulta indiscutible es que la generalización de "Constitución" en la modernidad se debe al constitucionalismo de corte liberal. Durante mucho tiempo la palabra "Constitución" se vinculó a una determinada visión del mundo; liberalismo era una palabra prestigiosa, ligada a una concepción ideológica determinada, que tiene en la libertad el centro de su universo. Hasta el fin de la II Guerra Mundial dicha noción y sus derivados no tienen particular prestigio fuera de los países que hoy diríamos de tradición liberaldemocrática. Los diferentes ismos -fascismo, nazismo, comunismo- le declararon la guerra sin cuartel. Acabada esa guerra con la victoria triunfante del constitucionalismo, se ensalza el término, que recobra su prestigio, al igual que sucede con el de "democracia". Inevitablemente, la generalización de todo término conduce tanto a su devaluación como a cierta pérdida de su significado.

El constitucionalismo y el liberalismo político son doctrinas políticas, movimientos de ideas. Son hijos del iusnaturalismo (siglos XVII y XVIII), de la Ilustración, y del contrato social. La palabra "Constitución" está ligada a los mismos, al triunfo de las ideas liberales mediante las revoluciones liberales que acontecieron, básicamente, en el siglo XVIII (y en adelante: 1830, por ejemplo). Si tuviéramos que resumir el constitucionalismo en tres ideas serían las que siguen. La primera es que el poder político debe emanar de los gobernados, traduciéndose en fuente de legitimidad de los gobernantes. El constitucionalismo lucha a brazo partido contra el absolutismo, donde el poder proviene de arriba, del soberano, del monarca absolutista. La segunda reside en que el objetivo de todo poder político es garantizar los derechos fundamentales, sirviendo de base para ello el artículo 2 de la Declaración Universal de los Derechos del Hombre y del Ciudadano. Esto es, garantizar la libertad, la propiedad privada, y el derecho de resistencia frente a la opresión. Cualquier otro fin se antoja secundario. Finalmente, la tercera se refiere a que el poder debe estar repartido, limitado. La teoría de la separación de poderes es capital en la concepción y distribución del

2 Vid. SARTORI, G; Elementos de Teoría Política, Alianza, Madrid, 2008, pássim. 
poder y los llamados checks and balances (frenos y contrapesos) se hacen imprescindibles.

No puede olvidarse que la visión de la naturaleza humana que late en el constitucionalismo tiene luces y sombras, sobre todo porque no es ni optimista ni totalmente pesimista. El poder se entiende como algo peligroso, como un mal necesario. No estamos ante el famoso buen salvaje de Rousseau sino que la experiencia demuestra que a las personas en general $-y$ a las que nos gobiernan en particular- que nos gobiernan debemos fijarles barreras y frenos para evitar que nos conduzcan al desastre. Pero no es totalmente pesimista porque no se resigna ante la constatación de la actitud del ser humano, ya que parte de la íntima convicción de que existe algún margen de acción de mejora.

Tampoco cabe obviar que el constitucionalismo no tiene mucho que ver con la democracia (ni directa ni representativa). Liberalismo no es sinónimo de democracia. El liberalismo es la limitación del poder mientras que la democracia es el gobierno del pueblo. Aunque a veces han ido de la mano, ni siempre ha sido así, ni necesariamente es así. Existe democracia sin liberalismo (Atenas; municipios italianos de la Edad Media; algunos cantones suizos; no así las autoproclamadas "democracias populares", donde habría más bien un abuso del término "democracia"). Y existe liberalismo sin democracia (los regímenes liberales originarios como los de 17890 1830). Cuando se unen estamos ante un matrimonio por interés y no por amor, en el sentido más noble de la palabra. Esto sigue sucediendo cuando llega el tercero en discordia (el componente social, la cláusula del Estado social), que no acaba de encajar en la extraña pareja. Así, Giannini, jurista italiano socialista, dejó por escrito que el Estado social era una noción perfectamente inútil, mientras que Forsthoff, conspicuo representante de la rama más reaccionaria del Derecho alemán, defendía con ardor la tesis de que introducir cuestiones sociales ponía en crisis el Estado de Derecho. ${ }^{3}$

\section{2.- Clasificación de las Constituciones}

¿Cómo podemos clasificar las Constituciones? El primer criterio es según quien hace y aprueba la Constitución. Conforme a este criterio tenemos Constituciones populares (aprobadas por el pueblo), y Constituciones otorgadas (no aprobadas por el pueblo, como por ejemplo el Estatuto Albertino de 1841). Esta clasificación tiene un carácter eminentemente histórico, al menos en Europa. El segundo criterio es según la forma que adopten. Bajo este tipo descansan Constituciones escritas (la mayor parte de ellas), y Constituciones no escritas (la excepción muy excepcional, casos de Reino Unido y de Israel). El tercero es según el procedimiento de reforma de la propia

\footnotetext{
3 Vid. FERNÁNDEZ-MIRANDA, A; "El Estado social", Revista Española de Derecho Constitucional, no 69, 2003, p. 146 y ss.
} 
Constitución. En este caso se habla de Constituciones flexibles y Constituciones rígidas. Las primeras son reformables siguiendo el procedimiento de producción de leyes ordinarias. Las segundas no son cambiables siguiendo tal procedimiento sino que se exigen procedimientos y trámites más gravosos (tales como mayorías reforzadas, dobles votaciones, y referéndums, entre otros). ${ }^{4}$

Las dos últimas formas están estrechamente relacionadas pero conviene no confundirlas. En los sistemas anglosajones -al menos en Reino Unido y Estados Unidos- cuando se dice "Constitución escrita" se está diciendo "Constitución rígida". Por ejemplo, en el caso McCulloch v. Maryland, de 1819, el Tribunal Supremo emplea tales términos como sinónimos. Los italianos, en cambio, hablan sólo de rigidez. Cada uso lingüístico es diferente pero el significante es el mismo: quiere decirse que estamos ante una Constitución que tiene carácter jurídicamente vinculante, no es un mero programa o folleto propagandístico, ni tampoco un panfleto político. Tiene vocación de ser aplicada directamente. En la tradición de estas Constituciones subyace la idea de que se está haciendo la misma consciente y voluntariamente. A pesar de lo obvio que puede resultar en la actualidad, existe una gran diferencia: sostener que es una norma fundamental es cuestión humana, sobre lo que los seres humanos pueden decidir y deciden; y esta idea no ha existido siempre, ni mucho menos. Por ello se liga a la escritura, haciendo ver que es una decisión consciente que quiere dejarse por escrito para poder fijar los términos de la lucha contra el absolutismo. Las primeras Constituciones escritas (la estadounidense de 1789 y la francesa de 1791) fueron profundamente antiabsolutistas: en el absolutismo los seres humanos no podían disponer de dicha norma fundamental (ni tan siquiera el monarca absoluto). Por lo demás, esa opinión ha sido moneda corriente dentro del mejor constitucionalismo que defiende que la escritura fue revolucionaria, un síntoma revolucionario más del liberalismo (constitucionalismo) contra el absolutismo.

Es necesario recordar que la rigidez no se basta por sí misma para garantizar la plena eficacia de las Constituciones. De ahí que se predique adicionalmente la supremacía, puesto que sitúa a la Constitución como primera Norma del Estado y fuente de legitimidad de todas las demás. Ambas cuestiones exigen que la reforma de la Constitución se realice por la vía procedimental estipulada y, en el caso de que no se siga, que exista el control judicial sobre el proceso para garantizar que este se reconduce, tarea que suele garantizar un Tribunal Constitucional. La rigidez necesita de la supremacía con carácter general aunque excepcionalmente encontremos Constituciones donde no se da tal feliz unión. Es el caso de la Carta

\footnotetext{
4 Un texto clásico es el de LOEWENSTEIN, K, Teoría de la Constitución, Ariel, Barcelona, 2018 (original de 1959) quien entendía que las constituciones válidas eran las normativas, no así las semánticas o las nominales, que tenían sólo el nombre y carecían del contenido, pássim.
} 
Canadiense de los Derechos y las Libertades de 1982, visión de compromiso donde la norma constitucional prevalece sobre el resto pero acepta que los derechos reconocidos se regulen por ley.

\section{3.- Elaboración y modificación de la Constitución}

Hay que abordar ahora la forma de crear una Constitución y la forma de revisar y actualizar la misma una vez creada. Con otras palabras, hay que abordar la elaboración y la modificación de la Constitución.

\subsection{1.- Elaboración de la Constitución}

La elaboración de la Constitución la realiza el poder constituyente. Sucede que la teoría clásica del poder constituyente parte de la idea de que dicho poder es originario, no deriva de poder anterior alguno, lo cual implicaría que no está jurídicamente regulado y por ende no limitado. Según esa doctrina estaríamos ante el ejercicio de un poder ilimitado, revelando quién es el soberano: el que ejerce el poder constituyente. Esta visión encontró arraigo al calor de un caso paradigmático: la Francia de 1789, en concreto del paso de los Estados Generales de junio a la Asamblea Nacional. De una asamblea puramente estamental se pasó a una asamblea de representantes de la Nación. Pero esto, que quizá fue válido para ese contexto histórico y político concreto no se puede trasladar fácilmente a otras realidades constitucionales comparadas.

Por ejemplo, no sirve para explicar la elaboración y aplicación de Constituciones federales, donde no hay una construcción teórica previa de una nación que necesita representación. Tampoco sirve para explicar aquellos sistemas constitucionales donde no se ha producido una ruptura radical con el anterior y son perfectamente constitucionales (no han tenido una Transición, como por ejemplo en España). ${ }^{5}$ Esto lo ilustra el ejemplo de Sudáfrica, donde su Constitución no rompe radicalmente con el apartheid. En tercer lugar, sus defensores ignoran los límites que impone el Derecho Internacional. Dejando de lado el ejemplo de la reunificación alemana -que se hizo bajo un tratado internacional-, lo cierto es que existen diversos derechos humanos reconocidos por los tratados internacionales, tratados jurídicamente vinculantes para los Estados firmantes. Es decir, las normas relativas a la protección de los derechos fundamentales imponen una serie de límites anteriores a todo poder constituyente. Buen ejemplo de ello es el artículo 6 del

5 Se analiza el proceso con detalle en SÁNCHEZ NAVARRO, Á; La transición española en sus documentos, CEPC, Madrid, 1998. Para leer una voz que aúna la doble condición de constitucionalista y protagonista en primera persona del proceso véase ALZAGA VILLAAMIL, Ó; "El proceso constituyente español visto por uno de sus protagonistas: entrevista a Óscar Alzaga Villaamil"; Historia constitucional, no 19, 2018, pp. 1-16. 
antiguo Tratado de Maastricht (hoy Tratado de la Unión Europea), que literalmente establece: "La Unión reconoce los derechos, libertades y principios enunciados en la Carta de los Derechos Fundamentales de la Unión Europea de 7 de diciembre de 2000, tal como fue adaptada el 12 de diciembre de 2007 en Estrasburgo, la cual tendrá el mismo valor jurídico que los Tratados". Por otro lado, la importancia que tiene el Convenio Europeo de Derechos Humanos y de la jurisprudencia interpretativa del Tribunal Europeo de Derechos Humanos queda fuera de toda duda, donde se está construyendo un orden público europeo basado en la protección de tales derechos. ${ }^{6}$

A mayor abundamiento, conviene tener presente el artículo 27 de la Convención de Viena que regula el Derecho de los Tratados, de 1980, donde se dice que: "una parte no podrá invocar las disposiciones de su derecho interno como justificación del incumplimiento de un tratado". Incluso se podría sostener que desde el Derecho Internacional se impone a los Estados tener una forma de gobierno concreta, la democrática. Así se deduce del artículo 21.3 DUDH, de 1948, donde se dice: "la voluntad del pueblo es la base de la autoridad del poder público; esta voluntad se expresará mediante elecciones auténticas que habrán de celebrarse periódicamente, por sufragio universal e igual y por voto secreto u otro procedimiento equivalente que garantice la libertad del voto". Otro tanto puede decirse del artículo 28 DUDH de 1948, que reza así: "Toda persona tiene derecho a que se establezca un orden social e internacional en el que los derechos y libertades proclamados en esta Declaración se hagan plenamente efectivos". ${ }^{7}$ ¿Qué sucede en el caso de que una Constitución, un poder constituyente concreto, se salte tales obligaciones? El Estado en cuestión debería hacer frente a las responsabilidades jurídico-internacionales que procedan, independientemente de que la validez de su Constitución fuera obviamente irrefutable.

Otro aspecto a tener en cuenta es que los últimos tiempos demuestran una cierta procedimentalización de la elaboración de las Constituciones (incluso en los casos de ruptura radical con la anterior). A veces provienen del interior y a veces del exterior. Ejemplo de lo primero es Sudáfrica, país que se dio unas normas constitucionales provisionales que rigieron mientras se hacía la Constitución. Incluso previeron crear un Tribunal Constitucional cuando todavía no había Constitución- cuya misión era certificar que el texto constitucional final se ajustaba a esas normas previas. Ejemplo de lo segundo es la cooperación constitucional internacional,

6 Vid. ÁlVAREZ RODRÍGUEZ, I; Brechas convencionales en España. Un reto constitucional del siglo XXI, Aranzadi, Cizur Menor, 2020; GARCÍA ROCA, J; La transformación constitucional del Convenio Europeo de Derechos Humanos, Aranzadi, Cizur Menor, 2019; y VVAA; "El Tribunal Europeo de Derechos Humanos"; Teoría y Realidad Constitucional, no 42, 2018, pp. 1-684.

7 Véase HIERRO, L; Los derechos humanos. Una concepción de la justicia, Marcial Pons, Madrid, 2016. 
que se da en momentos históricos de profundos cambios (por ejemplo, en Europa a partir del año 1989), donde para crear una Constitución se recibe todo tipo de ayuda y consejo de instituciones y grupos foráneos (por poner algunos ejemplos, la Comisión de Venecia, o la Organización para la Cooperación al Desarrollo). No es lo mismo, evidentemente, eludir las recomendaciones de tales organismos, que no dejan de evacuar recomendaciones no vinculantes, que incumplir un tratado internacional, auténtica norma jurídica cuyo incumplimiento produce consecuencias jurídicas de primer orden. Un ejemplo excepcional fue el caso de Kosovo, donde la Resolución 1244 del Consejo de Seguridad de Naciones Unidas, de 1999, permitía al Alto Comisionado modificar sus normas constitucionales. Ya se sabe que una golondrina no hace verano.

\subsection{2.- Modificación de la Constitución}

Al hablar de modificación, hablamos del poder de reforma/revisión, procedimiento que regula la propia Constitución. La mayor parte son rígidas, es decir, establecen procedimientos agravados de reforma, lo que evita poder reformarlas siguiendo el procedimiento legislativo ordinario. Esto obedece al deseo de otorgar estabilidad y garantizar que el núcleo básico constitucional permanece inalterado. A día de hoy apenas existen Constituciones flexibles (antiguamente se entendía que si una Constitución no decía nada sobre su propia reforma era flexible y por ende modificable por una ley ordinaria). La teoría clásica del poder de reforma habla, pues, de un poder no originario, derivado de la propia Constitución, limitado y jurídico; todo lo contrario, como puede verse, respecto del poder constituyente; estamos, en suma, ante un poder constituyente constituido. ${ }^{8}$

Los límites al mismo son de orden formal y de orden material. Respecto a los límites formales, las Constituciones prevén el procedimiento que hay que seguir para su propia reforma. Por ello se debe respetar todo lo que en él se diga en cuanto a trámites, plazos, requisitos y mayorías. En el caso de que no se haga la reforma podría ser invalidada (aunque esto plantea problemas adicionales, en los que no podemos detenernos, dado que se discute quién debería controlar que estos se cumplen así como con qué parámetros se hace: ¿se podría declarar una reforma constitucional inconstitucional - sería una contradicción en los términos dado que no cabe las normas autorreferenciales?

Respecto a los límites materiales cabe decir que su principal misión es dejar inalterados algunos preceptos, no tocar determinadas materias. Son las Ilamadas cláusulas de intangibilidad, como existen,

8 Nos siguen resultando muy estimulantes las reflexiones de KRIELE, M; Introducción a la teoría del Estado. Fundamentos históricos de la legitimidad del Estado constitucional democrático, Depalma, Buenos Aires, 1980. 
por ejemplo, en las Constituciones italiana, francesa o alemana. Cuestiones como la "forma de gobierno republicana", o "el Estado federal democrático y social" no pueden ser sometidas a revisión. Ello presenta, a su vez, problemas de otra índole. Uno es qué sucede si una Constitución no prevé límites materiales a su reforma. Algunos sostienen que, en ese caso, se podrían reformar todos los preceptos. Otros dicen que no, que aunque la Constitución no lo diga expresamente, reformarlos sería pura incoherencia (por ejemplo, el principio de la soberanía popular). Habría, entonces, límites implícitos. Lo que nos lleva a otro problema: ¿quién juzga que se han respetado tales límites? Dependerá de lo que cada ordenamiento diga. Es muy raro que las Constituciones reflejen quién es dicho juez, aunque sea perfectamente lógico hacerlo. La mayor parte de las Constituciones han optado por dejar tales cuestiones en silencio, quizá porque hay silencios que hablan por sí mismos.

Por lo demás, en este ámbito se plantea el problema que se plantea en toda norma que se aplica a sí misma, también conocido como la paradoja de Ross. ${ }^{9}$ Un modo de resolver dicha paradoja es acometer la reforma constitucional en dos fases. En la primera se reforma la norma constitucional que impide reformar las otras; y en la segunda se reforma ya frontalmente lo que se quería reformar en un principio con el impedimento constitucional removido. Pongamos por caso que quisiéramos cambiar en Francia su forma de gobierno y pasar de una República a una Monarquía. Para hacerlo sin romper el orden constitucional se debería, primero, reformar todos los preceptos constitucionales que impiden tocar la República como forma de gobierno $y$, hecho eso, acometer otra reforma constitucional para establecer la Monarquía como forma de gobierno.

\section{LA CULTURA CONSTITUCIONAL: CONCEPTO Y CARACTERES}

Dediquemos ahora el espacio pertinente a conocer cuáles son las aristas básicas del concepto de cultura constitucional y qué caracteres se apareja a la misma.

\section{1.- El concepto de cultura constitucional}

Huelga decir que el concepto de cultura es un concepto discutido y discutible. La RAE define cultura en su tercera acepción

\footnotetext{
${ }^{9}$ La cuestión supera con mucho el objetivo de este texto. Baste decir que el filósofo del Derecho danés, principal exponente de la escuela del realismo jurídico escandinavo, creyó observar que en ciertas Constituciones se producía una contradicción insalvable derivada de la aplicación de la norma constitucional a sí misma, especialmente en lo tocante a los procesos de reforma constitucional (en nuestro caso sucedería si quisiéramos reformar el artículo $167 \mathrm{CE}$, extremo que exige poner en marcha el propio artículo 167 CE). Vid. ALARCÓN CABRERA, C; "El "puzzle" constitucional de Ross en el marco teórico de las reglas constitutivas", Doxa: Cuadernos de filosofía del derecho, no 13, 1993, pp. 215-234.
} 
como: "conjunto de modos de vida y costumbres, conocimientos y grado de desarrollo artístico, científico, industrial, en una época, grupo social". Creemos que este es el que mejor se ajusta a los objetivos de este trabajo y por ende será el que empleemos a partir aquí, sin perjuicio de dejar anotado que las diferentes acepciones también han tenido su reflejo en las discusiones albergadas al calor del constitucionalismo y de cómo sus dos principales elementos (racionalidad y homogeneidad) se han visto sacudidos por diversos sucesos que han tenido lugar desde finales del siglo XX y principios del XXI. ${ }^{10}$

Podemos acotar un concepto siquiera mínimo de "cultura constitucional", como la unión de valores, principios, hábitos y prácticas que dan como resultado una Constitución, norma suprema de los Estados democráticos cuyos orígenes datan de los siglos XVII y XVIII, en concreto de los valores alumbrados mediante las tres revoluciones llamadas constitucionales: la de Inglaterra, la de Estados Unidos de América, y la de Francia. A partir de ahí, se implantaron en el mundo occidental esas Constituciones a lo largo del siglo XIX y especialmente en el siglo XX. ${ }^{11}$ Conviene no perder de vista una afirmación que con el paso del tiempo no ha hecho sino demostrar su vigencia: y es que allí donde hay una Constitución en vigor hay siempre un mínimo de cultura constitucional, por mínimo que sea, independientemente de la forma concreta que pueda adoptar o las desviaciones que pueda sufrir. ${ }^{12}$

Efectivamente, la formación de la cultura constitucional moderna se nutre del proceso de gestación del Estado y del individuo a lo largo del siglo XVII. A partir de ahí tales Estados evolucionan y pasan por diferentes fases que desembocan en eso que Peter Häberle ha estudiado en profundidad: la incorporación de la cultura a las Constituciones una doble acepción: el derecho como cultura y la cultura como derecho. Aquí vamos a ceñir el análisis a la primera vertiente, la cual el propio Häberle centra en cómo hace suyos los valores constitucionales la sociedad civil. ${ }^{13}$ En ese sentido, debemos destacar que la noción de cultura es algo más restringida que la noción de civilización. Pero se atisba un deseo desde el primer momento de querer ser útil. En la Inglaterra posterior a la revolución de Cromwell se sientan las bases. Un teórico como Hobbes dirá que el Estado debe aportar seguridad a los ciudadanos, lo cual demuestra a las claras que el Estado pretende ser un instrumento racional que

\footnotetext{
10 Vid. RUIZ MIGUEL, C; "El constitucionalismo cultural", Cuestiones Constitucionales, n० 9, 2003.

11 Vid. PEGORARO, L; "Constitucionalización del Derecho y cultura constitucional", Revista de Derecho Político, no 104, 2019, pp. 13-57.

12 Vid. CRUZ VILLALÓN, P; "Constitución y cultura constitucional", Revista de Occidente, no 211, 1998, pp. 11-22.

13 Vid. HÄBERLE, P; El Estado Constitucional, Instituto de Investigaciones JurídicasUNAM, México, 2011, cuando dice que "toda Constitución de un Estado constitucional vive en última instancia de la dimensión de lo cultural", p. 3.
} 
entiende al individuo como portador de derechos individuales, aunque tenga en mente un limitado modelo de varón-blanco-propietario, según nos recuerdan algunos autores. ${ }^{14}$

Desde parámetros constitucionales norteamericanos se nos ha dicho que la cultura constitucional es la caja negra donde la letra constitucional se transforma en consecuencias concretas; un conjunto interrelacionado de prácticas, acuerdos institucionales, normas y hábitos de conducta y de pensamiento que determinan las preguntas que formulamos, los argumentos que manejamos, cómo resolvemos las disputas. Como se puede ver, la empresa es complicada y por definición vasta y resbaladiza, pero no puede renunciar a establecer ciertas pautas. Por un lado, las acciones sobre el proceso constituyente se limitan en tiempo y espacio, dando lugar a una adaptación de las normas a la realidad social (los americanos hablan de su Constitución como de un living-tree, una norma viva que debe interpretarse conforme las exigencias de la sociedad actual en oposición a los originalistas, que abogan por ceñirse al significado literal de la letra constitucional que los founding fathers acordaron en 1787). Por otro, en ese proceso de adaptación influyen varios factores históricos, políticos, sociales y económicos. La Constitución, además, apela a argumentos racionales pero también refleja valores más profundos sobre lo que es de veras importante, lo que es posible y sobre cómo funciona el mundo realmente. No podemos estar más de acuerdo. ${ }^{15}$

El punto central de la cultura constitucional será la conjunción de dos valores que quedaron establecidos claramente a raíz de la Revolución francesa: el famoso artículo 16 de la Declaración de Derechos del Hombre y del Ciudadano, donde se decía que toda sociedad que carezca de separación de poderes y de garantía de los derechos individuales carece de Constitución. Ahí tenemos los dos pilares sobre los que se asienta el constitucionalismo moderno, tal y como hemos visto antes. Por un lado, el poder político debe estar separado y no quedar concentrado en las mismas manos ni desde el punto de vista horizontal ni desde el punto de vista vertical. No puede haber una sola persona que concite el mismo (eso sería una dictadura), ni tampoco puede haber miles de personas ejerciendo el poder (lo cual conduciría a una anarquía disfuncional). A partir de estos datos, ya estamos en condiciones de definir qué es cultura constitucional.

\footnotetext{
14 Por ejemplo, CLAVERO, B; Happy Constitution, Trotta, Madrid, 1997; y CALLE MEZA, M.L; "A propósito de la cultura constitucional", Revista de Derecho del Estado, no 25, 2010, pp. 223 y ss.

${ }^{15}$ Reflexiones que se toman de SIEGEL, A.W; "Constitutional Theory, Constitutional Cultural", 18 U. Pa. J. Const. L. 1068 (2016)-Seattle University School of Law Research Paper, 2016, p. 1107 y ss. También es muy ilustrativo el trabajo de TUSHNET, M; Why the Constitution matters, Yale University Press, London-New Haven, 2010.
} 
Para autores como el propio Häberle o Sagüés, la "cultura constitucional" es la suma de actitudes, ideas, valores y expectativas de una comunidad concreta, que determinarán su grado de desarrollo político y jurídico. ${ }^{16}$ En ese sentido Sagüés ha distinguido tres tipos de cultura constitucional: la cultura constitucional del constituyente al elaborar la Constitución; la cultura constitucional de los operadores de la Constitución, una vez se encuentra en vigor (administraciones, instituciones, tribunales); y la cultura constitucional de la sociedad, la que manifiestan los ciudadanos en su devenir cotidiano.

La cultura constitucional del poder constituyente tiene que ver con los valores que presidieron la discusión y redacción de la misma. Una Constitución acertará o no en la medida en que consiga evitar contradicciones y utopías, o proclamar derechos imposibles. Debe tenerse en cuenta que el plagio de otras Constituciones -cuestión diferente es la inspiración en lo que funciona- o el detallismo en la letra constitucional -más propio del legislador ordinario- no suelen ser garantía de éxito. Otro factor a tener en cuenta es la aceptación social de la ideología que la inspira. Si la sociedad en la que se inserta tiene fuertes rupturas y brechas ideológicas, el cariño constitucional será de geometría variable. Además, la Constitución debe ser compatible con un Derecho Internacional cada vez más impetuoso y exigente, aunque no puede renunciar al corazón básico del mejor constitucionalismo: la dignidad, la democracia, el control de constitucionalidad, o la transparencia. Una vez se adopta es fundamental conocer si ha sido impuesta o ha sido consensuada, así como velar porque se respete su letra a la hora de reformarla. El constitucionalista argentino nos recuerda que el poder constituyente irregular, tan típico de Carl Schmitt, no es compatible con el Estado constitucional de Derecho. ${ }^{17}$

La cultura constitucional de los operadores de la Constitución y de la sociedad viene marcada por lo que Konrad Hesse llamaba "voluntad de Constitución": la leal intención de cumplir con la ley suprema tanto por parte de los poderes institucionales como por parte de la sociedad civil. Claro que también se puede dar el polo opuesto y es la desconstitucionalización: la inexistencia o muy escasa voluntad de cumplimiento de la Constitución. Por parte de los operadores, porque se justifican alegando que lo hacen "por necesidad", no por placer, aplicando el Derecho de emergencia, con constantes delegaciones legislativas al Poder Ejecutivo, con la práctica reiterada de mutaciones constitucionales, abogando por la derogación sociológica y por las interpretaciones manipulativas. Por parte de la sociedad, porque se erosione la cultura constitucional hasta tal punto que se dan fenómenos de anomia social, con multitudes viviendo al margen de la ley. En casos límite se admite que podríamos saltarnos una Constitución impuesta o reglas

16 Vid. SAGÜÉS, N.P; "Cultura constitucional...", cit, p. 100 y ss.

17 Vid. SAGÜÉS, N.P; "Cultura constitucional...", cit, p. 103. 
gravemente injustas (recordemos a Radbruch: el Derecho extremadamente injusto no es Derecho). ${ }^{18}$ La principal conclusión que extrae nuestro autor es que sin una mínima base constitucional en los tres elementos -autores, operadores, sociedad- la Constitución está destinada al fracaso. ${ }^{19}$

Para el profesor Pegoraro, la cultura constitucional es "la cultura jurídica que acepta, vive, venera la superioridad de la Constitución, pero no de cualquier Constitución, sino solo la que acepta la división de poderes (poco), y, sobre todo, los derechos humanos, en sus interpretaciones más radicales hasta rechazar la democracia, la voluntad popular, el Estado, el propio Estado de Derecho, confiando en un poder -el judicial de control de constitucionalidad- estructurado en los siglos pasados para proteger estos valores- para imponer un núcleo ético esencial que orienta esos valores, los limita y a veces incluso los anula". De ahí que el autor entienda que la cultura jurídica constitucional de hoy pasa inevitablemente por la constitucionalización del Derecho. 20

Desde el final de la segunda guerra mundial la ampliación de los horizontes de la democracia constitucional ha sido una constante. Raro es el país que no quiere legitimarse, aunque sea por mera apariencia de cara a la sociedad internacional, con una Constitución. Dicho con otras palabras, el constitucionalismo se adopta en casi todas partes pero con la idea limitada de situar a la Constitución, real o ficticiamente, en lo alto de la cúspide normativa. Esto se aprecia en aquellos países que han abrazado las veleidades neoconstitucionalistas (con dosis de ingenio y rebosante ironía un reputado constitucionalista español siempre decía que le sobraba una "e"). ${ }^{21}$ Algunos países como Venezuela, Ecuador o Bolivia intentaron liderar la vanguardia del nuevo constitucionalismo latinoamericano, aprobando sus Constituciones a finales de los noventa y principios de

\footnotetext{
18 Para contextualizar tal aserto véase el trabajo de PÉREZ DE LA FUENTE, Ó; "El caso de los tiradores del Muro de Berlín. A vueltas con algunos debates clásicos de la filosofía del derecho del siglo XX", Cuadernos Electrónicos de Filosofía del Derecho, no 23, 2011, pp. 453-487.

19 Vid. SAGÜÉS, N.P; "Cultura constitucional...", cit, p. 106.

20 Véase PEGORARO, L; "Constitucionalización...", cit, pp. 15 y ss.

21 El neoconstitucionalismo es una suerte de intento de superar los postulados clásicos del constitucionalismo, yendo un par de pasos más allá en la "democratización" del poder y estableciendo diversas herramientas intervencionistas, presuntamente participativas y sociales que mejorarían la versión original. Al observar lo que ha sucedido de veras en países donde se ha pretendido implantar, el experimento es de todo menos alentador. No obstante, hay varios tipos de neo-constitucionalismo y no queremos pecar de injustos o de excesivos por nuestra propia y palmaria ignorancia Vid. COMANDUCCI, P; "Formas de (neo) constitucionalismo: un análisis metateórico", Isonomía, no 16, 2002, p. 89 y ss. En España pueden verse los trabajos de GARCÍA FIGUEROA, A; "El convencionalismo jurídico o la irrelevancia del juspositivismo"; Persona y Derecho: Revista de fundamentación de las Instituciones Jurídicas y de Derechos Humanos, no 79, 2018, pp. 71-114 y; "Neoconstitucionalismo y argumentación jurídica", Derecho PUCP: Revista de la Facultad de Derecho, no 79, 2017, pp. 9-32.
} 
los dos mil siguiendo estos postulados, pretendiendo definir al Estado en cuestión como algo cerrado en torno a la idea del socialismo del siglo XXI, negando lo que es de veras una Constitución (un conjunto de valores concretos), y estableciendo las bases de lo que vendieron como progreso y se transformó en ruina: judicialización invasiva de la política, elusión del control de poderes para aumentar sin cesar el poder del Gobierno, la pretensión de hacer vinculantes desde el punto de vista jurídico y de forma puramente unilateral palabras como dignidad, democracia o derechos humanos tales el derecho al agua o al paisaje, por mencionar dos, vertiente esta inspirada en considerar que los tratados internacionales son la fuente suprema que guiará los dictados de la Constitución neoconstitucional.

No son estas las únicas resistencias que se oponen al constitucionalismo de corte clásico. A veces han sido doctrinas tradicionalistas, donde unos derechos consuetudinarios muy arraigados en ocasiones hacen de muro de choque en diversos lugares a lo largo y ancho del globo (aunque en ocasiones tales derechos se incorporan a la Constitución como muestra de querer plasmar su valor social, no de lo contrario). También podemos decir algo similar del Derecho divino, fuente en ocasiones refractaria al constitucionalismo porque sitúan por encima de cualquier obra humana la obra de Dios. Otro tanto podríamos decir de regímenes totalitarios que niegan la más elemental dignidad humana, como el pretendido Derecho socialista o nazi. No obstante, salvo estos extremos, el constitucionalismo occidental siempre debe hacer un esfuerzo adicional por intentar comprender conceptos y palabras que fundamentan otras culturas. ${ }^{22}$

\section{2.- Caracteres de la cultura constitucional}

La cultura constitucional, tal y como hemos visto, es ese conjunto de valores y principios encaminados a hacer cumplir y asentar los dos pilares mencionados: los valores que salvaguardan la separación de poderes y los valores que conducen a respetar los derechos fundamentales de las personas. Como se puede ver son dos las vertientes de análisis. Por un lado, ¿qué exige la separación de poderes? Por otro, ¿qué conduce a garantizar que los derechos fundamentales sean auténticos principios vertebradores de las vidas de las personas? Cada país occidental ha respondido a esto de una manera diferente, pero, dentro de esa diferencia, existe un núcleo común que podemos sintetizar en los siguientes rasgos. No casualmente ambas esferas se encuentran estrechamente relacionadas: la separación de poderes rectamente entendida tiene por objeto el mejor gobierno de las personas y que estas puedan desarrollar sus proyectos de vida conforme estimen oportuno. Y una 22 Sobre el particular véase el esclarecedor trabajo de IGNATIEFF, M; Las virtudes
cotidianas. Orden moral en un mundo dividido, Taurus, Madrid, 2018. 
auténtica garantía de los derechos fundamentales implica unos ciudadanos informados, adultos, maduros y responsables que suponen un dique de contención respecto a los desmanes en los que puedan incurrir los que ostentan dicho poder.

\subsection{1.- En cuanto a la separación de poderes}

La cultura constitucional implica que el poder político sea ejercido por diferentes órganos, integrados a su vez por diferentes personas. Con carácter general, el origen de todos ellos reside en lo que podemos llamar legitimidad democrática: los ciudadanos eligen a sus gobernantes y estos gestionan los asuntos públicos. Es tradicional la división que se suele hacer entre las tres grandes funciones que cumpliría todo Estado democrático: el Poder Legislativo, elegido por los ciudadanos en elecciones libres y competidas, que tiene como misión elaborar las normas generales que afectan a la comunidad y que reciben el nombre de leyes. El Poder Ejecutivo, que también se llama Gobierno, cuya principal misión reside en gestionar los asuntos públicos ordinarios en el marco constitucional y legal. $Y$ el Poder Judicial, formado por el cuerpo de Jueces y Magistrados, que tiene como principal función dirimir los conflictos a la hora de aplicar esas leyes tanto en el día a día de los ciudadanos como por parte de tales poderes, así como entre ciudadanos y poderes.

La regla general es que tales poderes sean directa 0 indirectamente elegidos por los ciudadanos, lo cual dependerá del sistema político. Si estamos en una democracia parlamentaria, los ciudadanos elegimos a nuestros representantes, que integrarán el Poder Legislativo (Parlamento), y que serán quienes a su vez elijan al Presidente del Gobierno ( $y$ este a su vez al resto de miembros del Gobierno; ejemplos de estos son, con sus diferentes variantes idiosincráticas, el Reino Unido, Italia, Alemania o España, sin ir más lejos). ${ }^{23} \mathrm{Si}$ estamos en una democracia presidencialista, los ciudadanos eligen en paralelo y por vías diferentes -en todo caso pulcramente democráticas- al Parlamento y al Ejecutivo (EEUU). También algo parecido sucede en los sistemas semi-presidencialistas (Francia).

\subsection{2.- En cuanto a los derechos fundamentales}

Una cultura constitucional implica como condición indispensable que las personas puedan elegir los proyectos de vida que crean

23 Un estudio sobre el Parlamento moderno puede verse en TORRES MURO, I; "Constitución y Parlamento: notas para la comprensión de la institución parlamentaria en el siglo XXI", Revista de las Cortes Generales, no 87, 2012, pp. 744. Para ver la evolución de la relación entre el Parlamento y el Gobierno en los últimos y convulsos tiempos patrios véase GARCÍA-ESCUDERO, P; "Parlamento y Gobierno en tiempos de multipartidismo", Corts: Anuario de derecho parlamentario, no 33, 2020, pp. 183-209. 
oportunos, lo cual es tanto como decir que puedan desarrollar del mejor modo posible los derechos fundamentales que la Constitución les reconoce. Para eso, tal y como decía aquella Declaración francesa tan vigente siglos después, es que se garanticen los derechos de los que somos titulares. ¿Qué es garantizar un derecho? Tal y como ha dicho un reputado constitucionalista, un sistema constitucional no es aquel donde no se lesionan los derechos fundamentales sino aquel donde se ponen los medios suficientes para reparar las lesiones que inevitablemente se producirán en todo grupo humano como grupo humano que es. Con sus propias palabras: un país respetuoso de los derechos individuales no es aquel donde no se violan sino donde no se violan de manera sistemática y masiva. Esto es: "un país es respetuoso de los derechos cuando dispone de remedios globalmente efectivos frente a las inevitables vulneraciones singulares de aquellos. ${ }^{24}$

Cada Constitución reconoce y garantiza los derechos fundamentales a su manera pero también aquí se aprecian algunas garantías adicionales que redundan en un mejor disfrute por la ciudadanía. En primer término, se reconocen varios derechos a los ciudadanos del Estado en la propia Constitución ( $y$ en buena parte a los extranjeros, aunque depende del sistema en cuestión). Al ser la Constitución la norma suprema de un Estado, los derechos se blindan y así se impide que puedan ser eliminados o ampliamente restringidos por los poderes ordinarios mencionados arriba. En segundo término, los derechos más importantes gozan de mayores garantías. Por un lado, legales, pues solo por ley pueden regularse; y en ocasiones esas leyes deben gozar de mayorías muy cualificadas. Por otro, institucionales, creando órganos específicos para protegerlos (por ejemplo, el Defensor del Pueblo); finalmente, las garantías judiciales: los tribunales ordinarios conocen de las demandas que los ciudadanos interponemos para defender nuestros derechos si entendemos que han sido lesionados. Si tales tribunales no satisfacen nuestra pretensión tenemos acceso a los tribunales superiores, también llamados altos tribunales, tales como el Tribunal Supremo y, especialmente en derechos fundamentales, el Tribunal Constitucional. Incluso si no obtenemos resarcimiento en ellos existiría la posibilidad, al menos en potencia, de acudir a diferentes tribunales internacionales. En ocasiones, al Tribunal de Justicia de la Unión Europea, pero aquí goza de especial relevancia el Tribunal Europeo de Derechos Humanos. En resumen, y siguiendo a un jurista de renombre: sólo habrá un constitucionalismo global que sea auténticamente tal -lo que podemos traducir como: sólo habrá una cultura constitucional global real- si se garantizan los derechos fundamentales, corazón de la democracia del siglo XXI. ${ }^{25}$

24 DÍEZ-PICAZO, L.Ma; Sistema de derechos fundamentales, Aranzadi, Cizur Menor, 2014 (4a edición), p. 154.

${ }^{25}$ Vid. FERRAJOLI, L; Constitucionalismo más allá del Estado, Trotta, Madrid, 2018. 
La mejor cultura constitucional actual es heredera de la mejor tradición constitucionalista que sintetiza los valores y principios acuñados desde el siglo XVI y que se consolidan y difunden por el mundo occidental a partir de la segunda mitad del siglo $X X$, fenómeno que llega a nuestros días. No son pocos los países que intentan abandonar sistemas autoritarios o totalitarios y tienen claro que lo primero que deben hacer para volver a sentar las bases de una convivencia duradera es una Constitución (Afganistán, Irak, Kenia, Nigeria), con resultados de toda condición. Uno de los ejemplos que sigue asombrando al mundo y que sigue siendo faro que nos guía es el de Sudáfrica, país que en 1999 consiguió dotarse de una Constitución que permitió al pueblo sudafricano eliminar la discriminación racial que antes estructuraba la sociedad en forma de apartheid. La importancia de los valores constitucionales que se plasmaron en dicha Constitución y el valor y la altura de miras de algunos hombres (y mujeres) buenos fue digna de encomio y elogio y ayudó a que el país consiguiera salir de las tinieblas raciales. ${ }^{26}$

Esas características están presentes de una u otra forma en todos los sistemas constitucionales y se traducen en forma de valores. Tomaremos como referencia nuestra Constitución, lo cual nos servirá a su vez para apuntalar la hipótesis de que somos herederos de esa tradición, a pesar de que desde algunos lugares se sigue diciendo, con más ligereza que reflexión, que el nuestro es un pueblo atávico y bárbaro, afirmación que no resiste el menor análisis empírico y argumental. ${ }^{27}$

\section{3.- Los valores constitucionales}

Los valores constitucionales se desarrollan en un tipo de Estado concreto, el Estado social y democrático de Derecho (y este Estado se basa en los valores constitucionales en un claro proceso de retroalimentación). No obstante, son tres elementos diferentes que exigen análisis por separado, tanto cronológica como materialmente. Primero nació el Estado de Derecho, que es el Estado auspiciado por el liberalismo y que confía antes en el gobierno de las normas que en el gobierno de las personas, siempre sospechoso a sus ojos. Todos quedamos obligados por las normas, tanto los ciudadanos como los poderes públicos. El Estado democrático responde al deseo de las masas, que se manifiestan en el siglo XX especialmente, reclamando participación política y poder decidir en las mismas condiciones que los que participaban hasta entonces, que eran quienes tenían tierras y educación suficiente. En la actualidad, tal y como decíamos antes,

26 Sigue siendo sobrecogedor pero altamente recomendable el testimonio de SACHS, A; The Strange Alchemy Between Life and Law, Oxford University Press, Oxford, 2011.

27 Remitimos, de nuevo, a la obra de BLANCO VALDÉS, R; Luz..., cit, pássim, resaltando nuestro autor que los principales índices internacionales nos sitúen dentro de las democracias más consolidadas del mundo. 
un Estado democrático no solo es aquel donde los ciudadanos son quienes ostentan el poder político -bien para ejercerlo directamente, cosa extrañísima en una democracia constitucional del siglo XXI- bien para elegir a los representantes políticos -regla general de las mismas-. Un Estado democrático es aquel donde se respetan y garantizan los derechos fundamentales de las personas. Por eso tan cierto es que no hay Constitución sin democracia como que no hay democracia sin Constitución. ${ }^{28}$ Finalmente, el tercer componente es el Estado social o Estado del bienestar, una idea que se crea después de los horrores de las guerras mundiales y que viene a ser un pacto entre el mundo capitalista -reconocemos una serie de prestaciones públicas, económicas y de seguridad social, de derechos básicos en suma, a los trabajadores a cambio de que estos no hagan la revolución- mientras que los trabajadores renuncian a hacerle la revolución a su empleador ( $y$ al sistema en conjunto), contribuyendo a mantener una economía de mercado mediante la prestación de servicios laborales. En general, el Estado ayudará al ciudadano "desde la cuna a la tumba", con una serie de políticas públicas que tienen como fin combatir los fallos del mercado a la hora de suministrar bienes considerados de primera necesidad, asentados en cuatro pilares: educación, sanidad, vivienda y seguridad social. Sucede que este elemento va a depender de dos factores que conviene no olvidar: la voluntad política de implementar políticas públicas en tales áreas y la necesidad de tener fondos para sufragarlas. Si no existe una u otra, es complicado que los llamados derechos sociales no queden en papel mojado. 29

Como valores específicamente constitucionales tenemos los que podemos llamar el cuarteto indispensable: la igualdad (entendida como la eliminación de toda discriminación odiosa, porque la igualdad absoluta es en realidad no sólo imposible sino probablemente indeseable por ser profundamente anti-humana), la libertad, la justicia, y el pluralismo político. Todas las Constituciones que lo son de veras comprenden estos valores, de un modo u otro. Por ejemplo, en España el artículo 1.1 menciona los principios arriba referidos y artículos como el 7, el 8, o el 9.2 los concretan. Son valores indispensables para la convivencia sana y buena.

Además, tenemos los valores específicamente relacionados con el Estado de Derecho y que velan por algo tan sencillo y tan complicado a la vez como que se cumplan las normas que nos hemos dado. Así, artículos como el 9 de la Constitución española establecen unas elementales reglas del juego que no pueden cambiarse sobre la marcha. El primer apartado de este dice que "Los ciudadanos y los poderes públicos están sujetos a la Constitución y al resto del ordenamiento jurídico", por lo que no hay nadie por encima del

28 Vid. FERNÁNDEZ-MIRANDA, C; y FERNÁNDEZ-MIRANDA, A; Sistema electoral, Partidos políticos y Parlamento, Colex, Madrid, 2008 ( $2^{\mathrm{a}}$ edición), p. 15 y ss.

${ }^{29}$ FERNÁNDEZ-MIRANDA, A; "El Estado...", cit, pp. 156 y ss. 
Derecho. El apartado 3 establece literalmente que: "la Constitución garantiza el principio de legalidad, la jerarquía normativa, la publicidad de las normas, la irretroactividad de las disposiciones sancionadoras no favorables o restrictivas de derechos individuales, la seguridad jurídica, la responsabilidad y la interdicción de la arbitrariedad de los poderes públicos". Expliquemos brevemente el contenido de cada uno de ellos.

El principio de legalidad significa que los poderes públicos solo pueden hacer aquello para lo que estén habilitados por una norma. Recordemos que los ciudadanos estamos vinculados negativamente a las normas, esto es, podemos hacer todo aquello que no esté prohibido. Pero los poderes públicos están vinculados positivamente a las normas. Esto significa que solo pueden hacer aquello para lo que estén autorizados. El Derecho Constitucional siempre ha tenido un miedo cerval al poder, de ahí que no ceje en su empeño de fijarle límites, frenos, contrapesos, restricciones y diversas condiciones para evitar que se haga realidad la máxima atribuida a Lord Acton (el poder corrompe y el poder absoluto corrompe absolutamente). La jerarquía normativa implica que las normas se ordenan de más a menos. Manda más la norma más importante y esta es la Constitución. Después, en el siguiente escalón, tenemos la ley, norma aprobada por el Parlamento y que debe respetar lo que aquella establezca. Y luego están los Reglamentos, norma aprobada por el Gobierno y que debe respetar tanto lo que diga la ley como lo que diga la Constitución. La publicidad siempre es garantía de transparencia y dique de contención que evita excesos. Si hubiera normas secretas los ciudadanos no podríamos saber qué demandan de nosotros y en consecuencia, estaríamos a ciegas. Sólo las dictaduras mantienen en secreto normas. A tal fin existen los diarios oficiales (el BOE en España, el DOUE en la Unión Europea), donde se publican las normas pertinentes. La irretroactividad es un criterio clarificador para ordenar en el tiempo el Derecho. Con carácter general este debe aplicarse desde la aprobación y publicación de la norma para adelante. Solo podrá ser retroactiva una norma que beneficie a los individuos a los que se va aplicar; de ahí que la Constitución establezca que está prohibido que se apliquen aquellas disposiciones que sean sancionadoras o desfavorables para estos. La seguridad jurídica es un principio que está estrechamente ligado a los anteriores. Significa que las personas debemos estar en posición de conocer lo que las normas exigen de nosotros. Así sabemos a qué atenernos. Por eso, entre otros motivos, las normas deben ser públicas. Por eso, entre otras razones, el Código Civil establece que la ignorancia de las leyes no exime de su cumplimiento (art. 6.1). En otras palabras: la seguridad jurídica implica que podamos prever las consecuencias jurídicas de nuestros actos. Finalmente, la responsabilidad y la prohibición de arbitrariedad de los poderes públicos exigen que estos adopten las decisiones y políticas pertinentes en atención al marco jurídico vigente. Por eso son 
responsables -responden en Derecho por lo que hagan, tanto bien como mal- y por eso no pueden tomar esas decisiones "porque sí", sin anclaje normativo o sin anclaje en la más elemental razón -eso es la prohibición de la arbitrariedad. Recordemos, de nuevo, que la vinculación positiva de los poderes públicos al ordenamiento constitucional implica que sólo pueden hacer aquello que las normas autorizan.

Finalmente, debemos hacer mención de uno de los valores indispensables que está en la base de todos los valores explicitados hasta aquí: la dignidad humana, con reflejo expreso en el artículo 10 de la Constitución. Allí se reconocen dos cuestiones de la mayor importancia y que también aquí se muestran íntimamente relacionadas. Merece la pena resaltar su tenor literal: "la dignidad de la persona, los derechos inviolables que le son inherentes, el libre desarrollo de la personalidad, el respeto a la ley y a los derechos de los demás son fundamento del orden político y de la paz social".

Si nos fijamos bien, la dignidad se menciona como uno de los fundamentos del orden político y de la paz social pero no se define (como por lo demás, no se definen el resto de valores constitucionales, para permitir su adaptación flexible a las circunstancias cambiantes). $Y$ es que es realmente complicado poder definirla. Según una de las muchas acepciones del Diccionario de la Real Academia Española, nos quedamos con la que reza: "gravedad y decoro de las personas en el modo de comportarse". Esto es, que las personas nos tratemos unas a otras de forma que reconozcamos en el otro a un ser humano como nosotros. Que existe una esfera irrenunciable de humanidad a la que no podemos ni debemos acceder en el sentido de no transgredir, de respetar. Quizá sea este un concepto que se define mejor a la contra, diciendo lo que no es: no es dignidad humana todo lo que sucedió en el siglo $X X$, con sus muchas guerras, dos de ellas mundiales, y atrocidades sin par. Es gravemente atentatorio contra la dignidad humana torturar a una persona ( $y$ el torturador, al hacerlo, lesiona la de los dos implicados, la suya propia y la del torturado: es imposible salir indemne de según qué cosas). Así podríamos seguir hasta el infinito, pero quizá baste con recordar el imperativo categórico de Kant como uno de los que mejor captó en qué consistía: no hacer a los demás lo que no quieres que te hagan a ti; compórtate con los demás como querrías que los demás se comportasen contigo.

Finalmente, debemos destacar todos y cada uno de los valores que se traducen en derechos fundamentales concretos a lo largo de la Constitución y que constituyen también parte del acervo constitucional. Su análisis pormenorizado excede el objeto de estas líneas, pero podemos resaltar una idea de fondo y es que todos ellos constituyen, a su vez, el estatuto básico del ciudadano: la ciudadanía es el conjunto de derechos y deberes que los individuos de un Estado democonstitucional tenemos y que exige de nosotros una actitud 
ciertamente activa y virtuosa tanto para su disfrute como para dejar que los demás hagan lo propio.

\section{4.- MODELOS DE CULTURA CONSTITUCIONAL}

Según han podido decir algunos autores, como por ejemplo Melero de la Torre, los jueces son fundamentales en el proceso de que la sociedad siga los cánones constitucionales, una suerte de intermediarios privilegiados entre las normas y los ciudadanos. No obstante, destaca que incluso estos, al tener que motivar sus decisiones, se basan más -o deberían basarse más- en una cultura de la justificación y no tanto de la autoridad, donde se diga por los poderes públicos qué se hace y por qué se hace, antes que en el consabido "se hace porque puedo hacerlo". En ese sentido, Melero detecta tres culturas de la justificación, que nosotros aquí reuniremos en torno a dos polos en atención a la cultura constitucional: la diferencia entre sistemas de common-law y continental-law (aunque también existen ciertas diferencias internas en cada uno de ellos en las que ahora no podemos detenernos). ${ }^{30}$

\section{1.- Sistemas del common-law}

Los sistemas de common-law son sistemas basados en la idea de la costumbre y de la tradición, especialmente el británico. Recordemos que hablamos de uno de los hitos fundadores del constitucionalismo moderno cuando no existía modernidad: será en la Magna Carta de 1213 donde, por primera vez en la historia, se recoge el derecho a caminar erguido, en decir de Martin Kriele, también conocido como el derecho de habeas corpus. Y así se mantiene en la actualidad en todas las Constituciones del mundo (por ejemplo: artículo 17.3 CE) lo cual dice todo acerca de la utilidad y necesidad de tal derecho. ${ }^{31}$ Confían tanto en este aspecto consuetudinario que algunos países inspirados en esta tradición no tienen una Constitución escrita, como el mismo Reino Unido o Israel, salvando las distancias en este último caso que hay que salvar. Consecuentemente, estos sistemas tienen una amplia confianza en los jueces a la hora de aplicar el Derecho, hasta el punto de que sus resoluciones son tan fuente del Derecho como la norma escrita. Otra característica derivada de ese apego a la costumbre es que los legisladores suelen dictar muchas menos normas $y$, las que dictan, suelen tener una extensión razonable. Al menos hasta tiempos modernos (posmodernos), donde parecen haberse imbuido de cierta

30 MELERO DE LA TORRE, M; "Cultura constitucional". Eunomía. Revista en Cultura de la Legalidad, no 15, 2018-2019, pp. 224-230.

${ }^{31}$ KRIELE, M; Introducción..., cit, pássim. 
querencia por redactar normas cada vez más largas y farragosas. Afortunadamente, parece que es la excepción. ${ }^{32}$

\section{2.- Sistemas del continental-law}

Los sistemas del continental-law constituyen la otra gran tradición en el mundo del Derecho y tiene especial raigambre en el Viejo Continente también conocido como Europa. Aquí confiaremos mucho más en el Derecho positivo, en el Derecho escrito, y por ende todos los países tendrán su Norma Fundamental escrita. Además, en estos sistemas los jueces y magistrados gozan también de un prestigio intelectual fuera de toda duda pero quizá por miedo a los excesos que puedan cometerse, confiamos un poco menos en ellos y acotamos la tarea jurisdiccional al ordenamiento constitucional (artículo 117.1 CE). Aquí la jurisprudencia será también vinculante, claro está, pero no será con carácter general fuente del Derecho tal y como lo es en los sistemas del common-law.

\section{3.- Cultura constitucional y democracia}

Por lo demás, conviene advertir que igual de constitucional es un Estado donde hay una República que otro donde existe una Monarquía. Igual de constitucional es un Estado más intervencionista que otro que lo es menos. Lo mismo para un Estado poco, mucho o nada social, independientemente de las preferencias personales de cada quien. La Constitución permite que gobiernen programas de diferente signo ideológico, lo cual suele ser uno de los mejores termómetros para saber si hay o no una Constitución de veras. La Constitución establece el terreno de juego y las reglas básicas del mismo, pero no predetermina ni el juego en sí ni cómo deben jugarlo los sujetos participantes, siempre que respeten las líneas rojas establecidas por dicho marco. La Constitución establece el marco, pero el cuadro que se pinte, la técnica utilizada, las imágenes representadas, en fin, todo lo que pase dentro de ese marco, es legítimo desde el punto de vista constitucional, independientemente de que al ciudadano de a pie guarde su propia opinión al respecto. Discrepar es propio de ciudadanos reflexivos y críticos, por ende, ciudadanos constitucionales.

Esto tiene a su vez que ver con uno de los debates más interesantes -y probablemente irresolubles- que tienen lugar desde hace varias décadas: ¿hasta dónde puede llegar una democracia constitucional a la hora de tolerar a quienes no solo no comparten sus postulados sino que los socavan sin desmayo? Si la cultura constitucional es defender los valores básicos que hemos visto arriba,

32 Para el estudio del sistema constitucional británico véase LEYLAND, P; The Constitution of the United Kingdom: a contextual analysis, Hart Publishing, Oxford, 2007. 
¿qué hacemos con quienes defienden proyectos que atentan flagrantemente contra los mismos y que, si pudieran, los destruirían? Esto es, ¿necesitamos como condición sine qua non una cultura constitucional robusta y una democracia militante, o es posible mantener una cultura constitucional lábil y un sistema especialmente abierto? Aunque la Constitución no dice nada al respecto, ni establece cláusulas de intangibilidad que queden fuera de un proceso de reforma constitucional, nuestro Tribunal Constitucional ha interpretado que la democracia constitucional española no es una democracia militante y por ello se puede defender sin temor a sanción cualquier proyecto político que se desee, incluso uno que pretenda subvertir el orden constitucional al completo. ${ }^{33}$ Lo que no puede hacerse es defender ese o cualquier otro a través de medios violentos. Vale cualquier fin pero no vale cualquier medio. Muy probablemente esta postura quiera dar cabida a todas las sensibilidades existentes en un país tan diverso como el nuestro. No obstante, desde el año 1978 ya tenemos al menos dos experiencias bien duras y traumáticas de porqué, en realidad, toda democracia es y solo puede ser militante. Cuando ciertas opciones políticas deciden defender mediante un brazo terrorista fines políticos concretos, o cuando los gobernantes de ciertos territorios declaran unilateralmente la independencia de los mismos desgajándolos del resto de España saltándose todas las normas habidas y por haber, se nos sitúa a todos en un vacío jurídico donde no es que la lealtad constitucional brille por su ausencia, es que las consecuencias son potencial y realmente devastadoras. 34

\section{4.- ¿Es posible medir la cultura constitucional?}

Va de suyo que medir la cultura constitucional es harto complicado. No obstante, existen algunos esfuerzos protagonizados

\footnotetext{
33 Por ejemplo, en la STC 136/2018 (FJ 6) nuestro Juez de la Constitución recuerda que "en nuestro ordenamiento constitucional no tiene cabida un modelo de democracia militante, esto es, un modelo en el que se imponga, no ya el respeto, sino la adhesión positiva al ordenamiento y, en primer lugar, a la Constitución", lo cual ha reiterado desde la STC 48/2003, en las SSTC 5/2004; 235/2007; 12/2008; y $31 / 2009$. En una de las resoluciones dictadas al hilo del procés, el TC dejó sentado que "tienen cabida en nuestro ordenamiento constitucional cuantas ideas quieran defenderse y que no existe un núcleo normativo inaccesible a los procedimientos de reforma constitucional" [STC 42/2014, FJ 4 c)]. Da argumentos convincentes que entienden que la democracia es y solo puede ser militante FERNÁNDEZ-MIRANDA, C; y FERNÁNDEZ-MIRANDA, A; Sistema..., cit, p. 17 y ss.

34 Véanse los trabajos de la profesora BIGLINO CAMPOS, P; "Constitución y contrato social", Revista Jurídica de Castilla y León, no 47, 2019, p. 19 y ss.; y "Constitución y reglas del juego". En VVAA; Congreso Internacional Constitucional, CEPC, 2020, Madrid, p. 45 y ss. Otro tanto se deduce de las contribuciones de ARAGÓN REYES, M; "Significado de la Constitución Española de 1978", En VVAA; Congreso Internacional Constitucional, CEPC, 2020, Madrid, p. 33 y ss.; y MUÑOZ MACHADO, S; "Significado de la Constitución Española de 1978", En VVAA; Congreso Internacional Constitucional, CEPC, 2020, Madrid, p. 39 y ss.
} 
por la comunidad de expertos que han dedicado algunas reflexiones al particular. Por ejemplo, el profesor Sagüés propone un método basado en indicadores de cultura constitucional. ${ }^{35}$ Respecto a la cultura constitucional del constituyente, deberíamos estar en condiciones de responder hasta a once preguntas que desembocan en una solución u otra: si estamos ante una Constitución consensuada, exigible por sus beneficiados, posible, elaborada, clara, coherente, razonable, previsora, ceñida a lo esencial y personalista, e internacionalista, estamos ante una más que sólida cultura constitucional. Si estamos, por el contrario, ante una Constitución impuesta, mera promesa de los gobernantes, utópica, imitada, ambigua, contradictoria, irrazonable, imprevisora, detallista, transpersonalista y autista, entonces la cultura constitucional será bastante escasa.

Otro tanto puede decirse respecto a la cultura constitucional de los operadores jurídico-institucionales. Si gozan de voluntad de Constitución, se adaptan a las nuevas realidades, se producen reformas constitucionales con regularidad, se respeta la división de poderes, se respetan los derechos fundamentales, se cumplen las obligaciones constitucionales, las leyes aprobadas se ajustan al marco constitucional y se declaran inconstitucionales las normas que lo son, de nuevo la cultura constitucional resulta robusta. En cambio, si existe una desconstitucionalización del sistema, la interpretación constitucional es anacrónica, el poder constituyente es irregular, se producen deslizamientos inconstitucionales, se infringen con carácter general los derechos fundamentales, se reiteran las inconstitucionalidades por omisión o por negación, las leyes que se aprueban son inconstitucionales $y$ se convalidan expresa 0 tácitamente normas que son en verdad inconstitucionales, la cultura constitucional es bastante baja.

Finalmente, la cultura constitucional del pueblo, de la sociedad, es subsumible a tres afirmaciones: si tenemos voluntad de Constitución, cumplimos con nuestros deberes constitucionales y respetamos los derechos de los demás, la sociedad tiene una fuerte convicción constitucional. Ahora bien, si llevamos vidas desconstitucionalizadas, incumplimos los deberes constitucionales y lesionamos los derechos de los demás, no parece que hayamos desarrollado una cultura constitucional especialmente sólida.

\section{5.- BREVE APUNTE SOBRE LA CULTURA CONSTITUCIONAL EN ESPAÑA}

Llega el momento de posar la mirada en la cultura constitucional española. Para ello hemos decidido que puede ser un esquema útil reparar brevemente de dónde venimos, el cambio que supuso la Constitución de 1978 que determina el dónde estamos y,

35 Vid. SAGÜÉS, N.P; "Cultura constitucional...", cit, pp. 100 y ss. 
finalmente, algunos hechos que afectan cuando no directamente dañan la cultura constitucional.

\section{1.- Constitucionalismo histórico y cultura constitucional}

Por todos es sabido que la cultura constitucional en España ha tenido problemas para arraigar, tendencia que parece seguir presente en la actualidad. ${ }^{36}$ No hay más que ver el número de Constituciones y proyectos de Constituciones que hemos tenido desde el siglo XVIII en adelante para confirmar lo acertado de esa afirmación. La Constitución de 1978, actualmente vigente, es la última de un largo proceso que comienza allá por 1811, Norma que ya es la más longeva de nuestra atribulada Historia constitucional. Es conocido que nuestro constitucionalismo ha alumbrado varias Constituciones a lo largo de la Historia. La principal característica que une a todas ellas es que fueron superadas sin respetar su letra, no se reformaron para ir adaptando sus contenidos a los avances que la sociedad del momento iba experimentando. No fue infrecuente que se produjeran pronunciamientos militares o golpes de Estado que eliminaban de un plumazo el anterior régimen político e instauraban uno nuevo. Los españoles no hemos conseguido cuidar nuestras Constituciones, cuidado que pasa por la reforma gradual y puntual cuando se hace necesaria. 37

Hagamos un breve repaso histórico. En 1812 se dicta una de las primeras Constitucionales liberales del mundo, en Cádiz, a la que se le conoce con el sobrenombre de "la Pepa". Su valor simbólico fue alto, toda vez que era la apuesta del constitucionalismo frente al absolutismo. Desafortunadamente, no duró mucho, dado que en 1814 el monarca absolutista Fernando VII la deroga. Vuelve a entrar en vigor entre 1821 y 1823 pero en este último año se vuelve a derogar. De 1834 a 1836 rige el Estatuto Real hasta que se produce el Motín de La Granja, que alumbra en 1837 una nueva Constitución y que es el momento donde se intenta construir un verdadero régimen constitucional en España. Hubo varias Constituciones en vigor a partir de ese momento $(1837,1845,1869,1876,1931)$ y proyectos que no llegaron a serlo (1856, 1873). Aunque a primera

36 Así lo entiende MATIA PORTILLA, F.J; "Estado constitucional y democracia. Algunas consideraciones sobre la actual desafección hacia la clase política (ensayo)". En RUBIO LLORENTE, F; JIMÉNEZ CAMPO, J; SOLOZÁBAL ECHAVARRÍA, J.J; BIGLINO CAMPOS, P; GÓMEZ MONTORO, Á (coords). La Constitución Política de España: estudios en homenaje a Manuel Aragón Reyes, CEPC, Madrid, 2016, p. 183 y ss. Desde otro ángulo, algo más optimista, lo enfoca ORTEGA CARCELÉN, M; España en positivo, Servicio de Publicaciones de la Facultad de Derecho de la Universidad Complutense de Madrid, Madrid, 2018, p. 69 y ss.

37 El miedo atávico a la reforma constitucional ha sido una preocupación constante de nuestra doctrina. Véase ALZAGA VILLAMIL, Ó; "Fundamentos políticos, económicos y europeos de la constitución española de 1978 contra la alergia a la reforma constitucional". En MARTÍNEZ CUADRADO, M (dir); Reforma constitucional en la Unión Europea y en España, Marcial Pons, Madrid, 2019, pp. 77 y ss. 
vista parecía haber diversidad, la realidad mostraba que el armazón teórico de todas era muy similar entre sí. Hasta 1931, donde la II República intentó fraguar en torno a una Constitución que establecía una ruptura constitucional con las anteriores. ¿Qué la diferenciaba?

Los elementos comunes hasta entonces se centraban en un sistema territorialmente centralizado, con preferencia por la Monarquía, un poder legislativo bicameral, un régimen parlamentario y una muy escasa referencia a los derechos fundamentales. Ese fue nuestro siglo XIX. La inestabilidad que alumbró tantas Constituciones probablemente tenía más que ver con las maniobras de los políticos de turno que debido a grandes alteraciones del diseño constitucional. En otras palabras: elementos importantes de la clase política intrigaba a espaldas de la letra constitucional, que permanecía inmaculada hasta que se veía sorprendida con la entrada en vigor de otra nueva.

Es común leer que nuestras Constituciones han sido de dos clases, moderadas y progresistas. Según la comunidad de expertos, la distinción es bastante relativa. ${ }^{38}$ Si tenemos en cuenta su duración, en España han durado más las de corte moderado (setenta años frente a trece años). Además, ninguna fue realmente efectiva, por diversos motivos: los pronunciamientos militares se sucedían, el sufragio se falseaba (el famoso pucherazo lo inventamos nosotros, los españoles), el estado de sitio fue una constante. En fin, prácticas todas ellas altamente sospechosas desde un punto de vista constitucional rectamente entendido. En 1923 se viene el golpe de Estado de Primo de Rivera, quien se mantiene en el poder hasta 1930. En 1931 se produce el advenimiento de la II República con la Constitución del mismo año como bandera. Su regulación muestra un modelo radicalmente diferente al que veníamos teniendo: ahora se apuesta por el régimen republicano, no monárquico; por la descentralización territorial; por un sistema parlamentario unicameral; por el sufragio universal; por ser un modelo que reconoce a nivel constitucional por vez primera los derechos fundamentales a todos los ciudadanos, creando un recurso específicamente encaminado a su protección (el recurso de amparo). Se crea el Tribunal de Garantías Constitucionales, antecedente inmediato del actual Tribunal Constitucional, y máximo guardián de la Constitución republicana. En fin, una auténtica ruptura con el constitucionalismo anterior. En el año 1936 sobreviene la Guerra Civil, que dura hasta 1939, con el triunfo del sedicente bando nacional. Ese mismo año, se instaura en España el régimen franquista, personificado en la figura del general Francisco Franco. A lo largo del mismo se dictaron las Leyes Fundamentales, que no eran una Constitución, pero eran donde se establecían los principios

38 Lo resaltan las obras que al inicio del presente escrito consideramos imprescindibles, citando ahora dos: DÍEZ-PICAZO, L.Ma; Ordenamiento..., cit; y LÓPEZ GUERRA, L; La Constitución..., cit. 
básicos del sistema autoritario. Será con la última, con la Ley para la Reforma Política de 1977, cuando el régimen franquista se haga el harakiri. ${ }^{39}$

\section{2.- La Constitución de 1978 y la cultura constitucional}

Efectivamente, una vez fallece Franco se empieza a dar los pasos necesarios para que España abandone el franquismo e ingrese en el mundo democrático. $Y$ eso, a finales del siglo $X X$, significaba dotarse de una Constitución normativa que estableciese aquello que la Declaración francesa de derechos del hombre y del ciudadano hizo mundialmente conocido: la separación de poderes y el respeto y garantía a los derechos fundamentales de los ciudadanos. Así fue como la sociedad española inició en torno a 1975 un proceso que desembocó en la aprobación de la Constitución de 1978. Un proceso que se guio por las ganas, y probablemente la necesidad, que tenían los españoles del momento de superar las divisiones que tenían entre sí para crear un proyecto común que consiguiera establecer una casa donde varias generaciones pudiéramos convivir y crecer en libertad. A juzgar por el resultado, no cabe duda de que lo consiguieron.

Después de cuarenta y dos años de vigencia, la Constitución ha cosechado inmerecidamente algunos enemigos que no dejan de asestarla zarpazos a diestro y siniestro, probablemente en el intento de alcanzar algún tipo de rédito electoral a corto plazo que, si las circunstancias son propicias, quizá redunde en alguna reforma constitucional que blandir ante las generaciones futuras para poder decir que lo consiguieron. ${ }^{40}$ Hasta los expertos que están de acuerdo en realizar reformas constitucionales de calado entienden que las dificultades y circunstancias para ello hacen realmente complicado el deseo. Creemos que puede ser la panacea cuando no parece tal: los cambios constitucionales suelen ser buenos si son consecuencia de un pacto de las principales fuerzas políticas y de la ciudadanía, que reman en la misma dirección para consensuar primero y reformar

\footnotetext{
39 Dicha Ley tuvo repercusiones de largo alcance para diversas instituciones tales como el sistema electoral, que por ser las reglas del juego de una democracia no se han modificado estructuralmente ( $y$ si se ha hecho, sólo bajo amplias mayorías que de facto han sido auténticos consensos, quizá exceptuando la introducción en 2007 del principio de composición equilibrada de las listas electorales). Sobre la primera cuestión véase ALZAGA VILLAAMIL, Ó; "Sobre el origen de nuestro sistema electoral y sus secuelas en nuestros partidos y en la dinámica pública"; Teoría y Realidad Constitucional, no 45, 2020, pp. 113-138. Sobre la segunda véase ÁLVAREZ RODRÍGUEZ, I; Democracia equilibrada versus democracia representativa, Congreso de los Diputados, Madrid, 2012. Una actualización parcial de las tesis del segundo puede verse en Crítica del constitucionalismo feminista, Atelier, Barcelona, 2020; también véase ALDEGUER CERDÁ, B; "Democracia paritaria". Eunomía. Revista de Cultura en Legalidad, no 19, 2020, pp. 342-364.

40 Vid. FERRER MARTÍN DE VIDALES, C; y ÁLVAREZ RODRÍGUEZ, I; "40 años de Constitución. Una revisión bibliográfica", Revista de las Cortes Generales, no 107, 2019, pp. 361-381.
} 
después. ${ }^{41} \mathrm{Si}$ la reforma se queda en algo cosmético y estético, flavo favor le hará a nadie. Si la reforma es de calado, es probable que algunos aprovechen el debate para hacer las propuestas más peregrinas que aboquen a una situación manifiestamente inoperante cuando no de cierta toxicidad social (esperemos que nunca dramática, pero...). Si los cambios constitucionales no son medio sino fin y cuando no son consecuencia sino causa todo quedará, como se suele decir coloquialmente, en agua de borrajas. El profesor García Roca lo expresa así: "Cuando hablamos de reforma constitucional en España, no nos referimos únicamente a los procedimientos regulados en los artículos 167 y 168 CE sino a una perspectiva más amplia. Revisar las normas, regenerar las instituciones y recuperar los derechos puede reclamar reformas en normas de muy distinto rango, incluso a veces puede bastar con adoptar buenas prácticas como ocurriría con una más exigente designación de los titulares de los órganos del circuito de garantías. Del mismo modo, no creo sea la opción más conveniente una única reforma constitucional de objeto múltiple, una hiedra de muchas cabezas imposible de explicar a la opinión pública (...). Es una explicación plausible creer que sería más sencillo ir aprobando algunas reformas parciales por paquetes. Pero sólo contemplando los problemas desde arriba y sin desdeñar la reforma de la Constitución como fuente del Derecho pueden hallarse soluciones. La mera ingeniería constitucional ya se ha revelado insuficiente en sucesivos intentos (...) y sabemos las distorsiones que genera". 42

¿Significa esto que los españoles carecemos de cultura constitucional y que simplemente estamos esperando la oportunidad, agazapados o emboscados, para dejar que nuestras pasiones nos dominen y acabemos de nuevo en un reguero de sangre? Nada más lejos de la realidad, desde la que se demuestra que el ciudadano corriente, paciente y trabajador como pocos, no está en hacer ninguna revolución sino en intentar salir adelante dando la mejor versión de sí mismo. Los discursos de ciertas élites no se compadecen con dicha realidad y luego se extrañan, estupefactas, de que su apoyo social mengüe hasta convertirse en irrelevantes. En el día a día de las personas podemos hacer la vida que hacemos desde que nos levantamos hasta que nos acostamos porque existe Constitución y porque todos, a nuestra manera, hemos interiorizado unos valores civilizatorios y constitucionales que lo refuerzan. Nos montamos en el Metro y vamos a nuestros trabajos sin despedazarnos los unos a los otros precisamente porque eso es así y no de otra forma. Si fuera de otra manera, apenas se podría salir a la

\footnotetext{
${ }^{41}$ El lector que desee profundizar en estas tesis puede consultar la obra de ALZAGA VILLAAMIL, Ó; Del consenso constituyente al conflicto permanente, Trotta, Madrid, 2011.

42 Vid. GARCÍA ROCA, J; "Los riesgos de una buena Constitución vieja: tiempos de reformas y democracia de consenso"; Revista de las Cortes Generales, no 106, 2019, p. 166.
} 
calle. Problemas ha habido, hay y habrá. Pero debemos huir de quienes dicen que la Constitución es un problema precisamente porque quienes lo hacen o son malévolos o estúpidos o la necedad más ignorante les nubla el juicio. Se ha demostrado en el mundo occidental que una Constitución es garantía de limitación del poder, progreso, respeto entre ciudadanos y desarrollo, de lo que se deduce que la Constitución es la solución y no el problema y que sin ella estamos abocados al desastre. ${ }^{43}$ Y como lo anterior quedaría en una opinión más, intentemos darle algún soporte argumental con datos en la mano.

Algunos estudios sociológicos realizados en los años noventa y los dos mil recuerdan que el $90 \%$ de españoles prefería la democracia a cualquier otro sistema. La Transición era un motivo de orgullo para casi el $80 \%$ de personas encuestadas. No obstante, dejaban ya una sombra de preocupación: un $68 \%$ no estaba interesado en la política mientras que en torno al $75 \%$ veían la Constitución como un documento lejano y desconocido, producto del trabajo de expertos y técnicos. ${ }^{44}$ En 2018 el CIS volvió a preguntar a los españoles. Casi el $70 \%$ de manifestó de nuevo orgulloso sobre la Transición. Y sobre la Constitución se demuestra que la quieren y la respetan, aunque desean su mejora (la mejor forma de mantener algo vivo, por otro lado). Casi un $70 \%$ se muestra globalmente satisfecho con ella, aunque en torno al $50 \%$ la reformaría en cuestiones importantes. Dentro de este sector, un $33 \%$ creen que la coordinación en educación y sanidad debe mejorar. Casi un $30 \%$ entienden otro tanto respecto a la transparencia y al control de la actividad política. Y en torno al $23 \%$ defiende reforzar la protección de los derechos sociales. ${ }^{45}$ En definitiva, existe un amplio respaldo social a la Norma aunque no es menos cierto que dicho respaldo mengua conforme pasa el tiempo.

Por otro lado, los intentos de que sea la Educación la que lidere el proceso de transmisión y consolidación de valores constitucionales

\footnotetext{
43 Tal y como dice Ricardo Moreno, la Constitución es el dique de contención que impide que los gobernantes hagan excesivo daño a los gobernados, de ahí que deba ser una norma estable que solo debiera cambiar por razones muy sólidas que conduzcan a una mejora de todos y no de unos pocos. Vid. MORENO CASTILLO, R; Breve tratado sobre la estupidez humana, Fórcola, Madrid, 2018, p. 32 y ss. Por lo demás, el propio autor entiende más dañina la estupidez que la maldad, en la medida que la segunda se puede combatir porque actúa con cierta lógica, cosa que no puede decirse de la primera (p. 18).

44 Los sectores críticos entienden que la participación política era la asignatura pendiente de la ciudadanía, para más señas herencia de la dictadura durante 40 años, y que esa despolitización de ayer es la falta de cultura constitucional de hoy. Vid. RUIZ-HUERTA CARBONELL, A; "La enseñanza de la Constitución en España: por una cultura constitucional"; Revista Jurídica de Castilla y León, no extra 1, 2004, p. 280 y ss.

45 Véase CIS; "Barómetro de septiembre de 2018-Estudio 3223", septiembre de 2018, $\quad$ p. 6 y $\quad$ ss. http://www.cis.es/cis/opencms/ES/NoticiasNovedades/InfoCIS/2018/Documentacio n_3223.html. Último acceso: 20/10/2020).
} 
(¿qué tendrá educación que siempre es la solución?) parece topar con ciertas resistencias sociales y políticas. Pongamos dos ejemplos. Cuando se aprobó la creación de la asignatura Educación para la Ciudadanía las críticas arreciaron desde diversos lugares. Casi todos confluían en el mismo punto: el Estado no puede adoctrinar a niños y jóvenes. El Tribunal Supremo hubo de decidir la controversia, declarando la licitud de la materia. ${ }^{46}$ El Tribunal entiende que los padres no pueden imponer sus derechos por encima de la enseñanza básica obligatoria, aunque gozan del derecho, en base al artículo 27 $\mathrm{CE}$, de evitar el adoctrinamiento de sus hijos. Para saber dónde acaba la primera y empieza lo segundo traza una distinción capital: los derechos fundamentales. El Tribunal Supremo entiende que los valores que dan base moral al sistema constitucional tienen traducción en los derechos fundamentales. Estos son indisponibles y, por ende, los discentes deben conocerlos y los padres no pueden negarse a ello. La conclusión es que, al enseñarlos, no cabría hablar de adoctrinamiento. El segundo grupo son el resto de valores, los que explican el pluralismo de la sociedad. Es aquí donde habría que guardar diversas cautelas. En palabras del propio Tribunal: "informando y no adoctrinando sobre las principales concepciones culturales, morales o ideológicas que, más allá de este espacio ético común, puedan existir en cada momento histórico dentro de la sociedad y transmitir a los alumnos la necesidad de respetar las concepciones distintas a las suyas" (FD 6).

Dicho de otra forma, no habrá adoctrinamiento en el primer caso, y será lícito constitucionalmente hablando la exposición de tales valores en términos de promover la adhesión a los mismos (se puede hacer proselitismo). En el segundo caso, los valores discutibles deben ser expuestos de manera rigurosamente objetiva y con la única finalidad de instruir (no cabe hacer proselitismo). En este caso, por seguir las palabras de la propia sentencia, se debe informar a niños y jóvenes "con la más exquisita neutralidad y el más prudente distanciamiento" (FD 11).

Pasado el tiempo, la polémica volvió a surgir con el llamado pin parental, referido a la posibilidad de que los padres puedan vetar que sus hijos acudan a según qué actividades extraescolares si entienden que van a ser adoctrinados en opciones ideológicas concretas con las que no comulgan. De nuevo resonaron los ecos de una polémica muy similar: mientras que los defensores del pin parental alegaban objeción de conciencia legítima y derecho a la libertad ideológica y

46 El Tribunal Supremo dictó cuatro sentencias, todas el 11 de febrero de 2009, para resolver el asunto. El leading-case, con ponencia del Magistrado Lucas Murillo de la Cueva, es la STS 340/2009, de 11 de febrero. Véase RUANO ESPINOSA, L; "Las Sentencias del Tribunal Supremo de 11 febrero 2009 sobre objeción de conciencia a EpC"; Revista General de Derecho Canónico y Derecho Eclesiástico del Estado, no 20, 2009. 
religiosa, los detractores alegaban que los niños deben ser educados en valores democráticos imprescindibles e indiscutibles. ${ }^{47}$

\section{3.- Los daños a la cultura constitucional}

En los últimos lustros no han dejado de suceder "cosas" que, de un modo u otro, han erosionado los valores constitucionales. No podemos realizar el análisis con la exhaustividad que merece pero estamos en condiciones al menos de enumerar algunas de esas "cosas" para trasladar una composición de lugar al lector y que sea este quien decida soberanamente.

El 11 de septiembre de 2001 se reinició la Historia, al decir del filósofo José Luis Pardo, quien ha elaborado uno de los mejores diagnósticos de lo que nos pasa. ${ }^{48}$ La sacudida que sufrió la democracia norteamericana, la posterior reacción en forma de dos guerras en Afganistán e Irak, y el caldo de cultivo que se generó en aquellos momentos no sólo socavó algunos valores constitucionales de la propia democracia estadounidense sino que la onda expansiva afectó de diversas maneras a los países occidentales, con un repliegue hacia posiciones netamente "securitarias". Lo cual condujo a una cierta contracción de los derechos fundamentales y a una acumulación del poder en manos del Ejecutivo en detrimento del Parlamento, tendencia que igualmente permeó otras democracias constitucionales, acentuando una tendencia anotada de largo por los expertos. 49

Estando la democracia liberal en baja forma, vino una crisis económica en 2008 que arrasó con millones de empleos y de industrias y cuya duración se extendió durante lustros. Cuando parecía que los países levantaban la cabeza, sobrevino la pandemia mundial provocada por la COVID-19, que azotó con una dureza que la falta de costumbre -y tantas otras cosas- ha hecho si cabe más dramática. Todas las voces coinciden en que sobrevendrá otra crisis económica y será de las que hagan época. De nuevo, desempleo,

\footnotetext{
47 La cuestión está atravesada por varios debates que han gozado de especial auge en la comunidad feminista y LGTBIQA+. Dicho de forma obligadamente resumida, mientras que estas tesis defienden que los niños reciban cierta educación en opciones vitales "diferentes a las normativas" haciendo valer el principio de igualdad y no discriminación, sus opositores entienden que tal extremo es un ejercicio de proselitismo inaceptable por llevarse a cabo con las mentes más vulnerables e indefensas. Vid. ÁLVAREZ RODRÍGUEZ, I; Crítica...cit, p. 180 y ss.

48 Vid. PARDO, J.L, Estudios del malestar. Políticas de la autenticidad en las sociedades contemporáneas, Anagrama, Barcelona, 2016.

49 Vid. FERNÁNDEZ-MIRANDA, C; y FERNÁNDEZ-MIRANDA, A; Sistema...cit, p. 163 y ss. Referencias obligadas del debate en la actualidad son las de RUNCIMAN, D; Así termina la democracia, Paidós, Barcelona, 2019; ZIBLATT, D; y LEVITSKY; S; Cómo mueren las democracias, Ariel, Barcelona, 2018; MOUNK, Y; El pueblo contra la democracia: porqué nuestra libertad está en peligro y cómo salvarla, Paidós, Barcelona, 2018; y KEANE, J; Vida y muerte de la democracia, Fondo de Cultura Económica, Ciudad de Méjico, 2018.
} 
carencia, quizá miseria. En ese contexto, el suelo que pisan las democracias se vuelve mucho más resbaladizo porque las tensiones sociales están a flor de piel, gobernar se convierte en algo parecido a atrincherarse y el clima que se respira se envilece. Si la tendencia a la hiperproductivad y al culto al yo ya campaba por sus respetos ( $y$ sus claroscuros también, con un número creciente de personas bajo tratamiento anti-depresivo) lo que puede venir a raíz de tales acontecimientos no es muy halagüeño. ${ }^{50}$ Por no mencionar que las principales opciones ideológicas que se abren paso hacen gala de un populismo rampante que cada vez vive más polarizado y donde una buena idea se convierte como por arte de magia en un arma arrojadiza que lanzar contra el enemigo (otro síntoma de la erosión de esos valores: de adversarios y rivales políticos a enemigos irreconciliables, en la más pura -y destructiva- lógica schmittiana). Guerra contra el hombre. Guerra contra la mujer. Guerra contra la tradición. Guerra contra lo novedoso. Guerra contra todo y contra todos. $Y$ de nuevo, algunos valores constitucionales tales como la libertad de expresión se resienten y lo que hasta hace no mucho parecía una tesis exagerada hoy ya se dice alto y claro: estamos volviendo a vivir tiempos inquisitoriales, de censura y de actitudes reaccionarias. Sólo que ahora han cambiado de bando y quienes antes las sufrían ahora las ejercen. Cuando un valor tan sensible como este entra en disputa es porque algo que late muy al fondo de nuestro corazón constitucional no funciona como debería. Algo probablemente oscuro y en cierta medida peligroso y a lo peor monstruoso. 51

En ese contexto, algunos países han tenido sus propias crisis dentro de las crisis. En España sobrevino el movimiento $15-M$ en 2011, marcadamente desde sensibilidades de izquierda que se manifestaron contundentemente contra los excesos del modelo capitalista y que tuvieron su correlato en forma de partido que a día de hoy hace bandera contra lo que llama candado constitucional, independientemente de que dicho candado sea el que haya permitido que llegue a responsabilidades de gobierno. Por lo demás, aquellos días fueron complicados y la situación social se caldeó hasta el punto de dar pábulo a actitudes que, en honor a la verdad, poco tienen que ver con una cultura constitucional sana (verbigracia, los escraches). La reacción contra la reacción produjo también movimientos en el espectro de la derecha, traducidos en nuevas formaciones políticas, algunas con más querencia que otras por la Constitución.

50 Sobre tales cuestiones, véase HAN, B-C; La sociedad del cansancio, Herder, Barcelona, 2012, aunque la idea es recurrente en la totalidad de su obra.

51 Para tomar el pulso a este debate puede verse MURRAY, D; La masa enfurecida. Cómo las políticas de la identidad llevaron al mundo a la locura, Península, Barcelona, 2020; KAISER, A; La neoinquisición. Persecución, censura y decadencia cultural en el siglo XXI, Deusto, Barcelona, 2020. GAMPER, D; Las mejores palabras. De la libre expresión, Anagrama, Barcelona, 2019; y OVEJERO, F; La deriva reaccionaria de la izquierda, Página Indómita, Barcelona, 2018. 
Anteriormente, España sufrió su propio 11-S con el 11-M, en 2003, y años después siguió dentro del itinerario terrorista cuando Barcelona sufrió un atentado en plenas Ramblas en el año 2017 que segó la vida de varias personas. Tales atrocidades seguían la estela de las que golpearon brutalmente en reiteradas ocasiones el Reino Unido, Francia, Bélgica u Holanda, en una campaña del terrorismo de corte islamista con cada vez más grupos reivindicando la necesidad de la guerra santa.

Por lo demás, ciertas prácticas de nuestra cotidianidad no dejan de causar estupor a la par que lesionan los valores constitucionales referidos. No dar cumplimiento a lo que exigen de nosotros los tratados internacionales que hemos firmado es preocupante. Dilatar sin motivo el nombramiento de los cargos institucionales por parte de los órganos constitucionales competentes es ya parte de un paisaje no menos preocupante. Por no mencionar que tales instituciones están integradas por algunas personas que no creen en ellas y que harán todo lo posible por propiciar su demolición. El juego democrático implica que el ciudadano medio deba tolerar, mal que le pese, opciones que no comparte. Pero el juego democrático no permite y el ciudadano medio no tiene por qué asumir que saltarse las reglas de dicho juego forma parte del mismo. Una porción del respeto constitucional con el que hemos convivido durante décadas se ha perdido y lo peor es que no sabemos si lograremos hacerlo volver.

\section{6.- REFLEXIÓN FINAL}

De lo que se ha dicho en líneas anteriores resaltamos una idea que, como toda buena idea, no importa las veces que se repita si es buena de verdad. Vivir bajo el paraguas de una Constitución es vivir en condiciones medianamente humanas. Así se ha demostrado en el paradigma occidental desde hace siglos. Limitar el poder político y gozar de auténticos derechos fundamentales son las dos piedras angulares que tratan a las personas como lo que son (y no como algunos dicen que deberían ser): como seres humanos contradictorios y volubles, cambiantes, a veces caprichosos, pero siempre y en toda circunstancia y condición merecedores de respeto. La comunidad africana tiene la palabra Ubuntu para definir lo que nosotros conocemos como dignidad (o quizá algo más que la mera dignidad): humanidad hacia otros. El único sistema conocido que respete de veras esa humanidad hacia otros es el constitucional. Dota a las personas de un impresionante acervo de derechos para que realice el proyecto de vida que estime mejor. Al mismo tiempo intenta embridar a quienes mandan para que, entre otras cosas, no puedan impedirlo. Por eso los procesos de "ruptura" constitucional son tan sospechosos: es imposible pretender eliminar una Constitución y seguir viviendo como si nada hubiere pasado, o incluso creer que mejor. La Constitución es esa norma que permite que 
hagamos la vida que a diario sin despedazarnos mutuamente. A nada que se piense en perspectiva histórica, no es en absoluto una cosa menor ni sencilla. Robustecer y consolidar la cultura constitucional que anida en todos los que hemos tenido la inmensa fortuna de vivir bajo una Constitución sólo puede traer cosas buenas. Hacer el trayecto contrario nos va acercando peligrosamente al borde del precipicio.

¿De qué lado se decantará la balanza?

\section{7.- BIBLIOGRAFÍA}

ALARCÓN CABRERA, C; "El "puzzle" constitucional de Ross en el marco teórico de las reglas constitutivas", Doxa: Cuadernos de filosofía del derecho, no 13, 1993.

ALDEGUER CERDÁ, B; "Democracia paritaria". Eunomía. Revista de Cultura en Legalidad, no 19, 2020.

ÁLVAREZ RODRÍGUEZ, I; Crítica del constitucionalismo feminista, Atelier, Barcelona, 2020.

ÁLVAREZ RODRÍGUEZ, I; Brechas convencionales en España. Un reto constitucional del siglo XXI, Aranzadi, Cizur Menor, 2020.

ÁLVAREZ RODRÍGUEZ, I; Democracia equilibrada versus democracia representativa, Congreso de los Diputados, Madrid, 2012.

ALZAGA VILLAAMIL, Ó; Del consenso constituyente al conflicto permanente, Trotta, Madrid, 2011.

ALZAGA VILLAAMIL, Ó; "El proceso constituyente español visto por uno de sus protagonistas: entrevista a Óscar Alzaga Villaamil"; Historia constitucional, no 19, 2018.

ALZAGA VILLAMIL, Ó; "Fundamentos políticos, económicos y europeos de la constitución española de 1978 contra la alergia a la reforma constitucional". En MARTÍNEZ CUADRADO, M (dir); Reforma constitucional en la Unión Europea y en España, Marcial Pons, Madrid, 2019.

ALZAGA VILLAAMIL, Ó; "Sobre el origen de nuestro sistema electoral y sus secuelas en nuestros partidos y en la dinámica pública"; Teoría y Realidad Constitucional, no 45, 2020, pp. 113-138.

ARAGÓN REYES, $M$; "Significado de la Constitución Española de 1978", En VVAA; Congreso Internacional Constitucional, CEPC, 2020, Madrid.

BIGLINO CAMPOS, P; "Constitución y contrato social", Revista Jurídica de Castilla y León, no 47, 2019.

BIGLINO CAMPOS, P; "Constitución y reglas del juego". En VVAA; Congreso Internacional Constitucional, CEPC, 2020, Madrid.

BLANCO VALDÉS, R; Luz tras las tinieblas. Vindicación de la España constitucional, Alianza, Madrid, 2018.

COMANDUCCI, P; "Formas de (neo) constitucionalismo: un análisis metateórico", Isonomía, no 16, 2002. 
CALLE MEZA, M.L; "A propósito de la cultura constitucional", Revista de Derecho del Estado, no 25, 2010.

CARCELÉN, M; España en positivo, Servicio de Publicaciones de la Facultad de Derecho de la Universidad Complutense de Madrid, Madrid, 2018.

CLAVERO, B; Happy Constitution, Trotta, Madrid, 1997.

CRUZ VILLALÓN, P; "Constitución y cultura constitucional", Revista de Occidente, no 211, 1998.

DÍEZ-PICAZO, L.Ma; Ordenamiento constitucional español, Tirant lo Blanch, Valencia, 2020.

DÍEZ-PICAZO, L.Ma; Sistema de derechos fundamentales, Aranzadi, Cizur Menor, 2013 (4a edición).

DÍEZ-PICAZO, L.Ma; y ELVIRA PERALES, A; La Constitución de 1978, Iustel, Madrid, 2008.

FERNÁNDEZ-MIRANDA, A; "El Estado social", Revista Española de Derecho Constitucional, no 69, 2003.

FERNÁNDEZ-MIRANDA, C; y FERNÁNDEZ-MIRANDA, A; Sistema electoral, Partidos políticos y Parlamento, Colex, Madrid, 2008 (2a edición).

FERRAJOLI, L; Constitucionalismo más allá del Estado, Trotta, Madrid, 2018.

FERRER MARTÍN DE VIDALES, C; y ÁLVAREZ RODRÍGUEZ, I; "40 años de Constitución. Una revisión bibliográfica", Revista de las Cortes Generales, no 107, 2019.

GAMPER, D; Las mejores palabras. De la libre expresión, Anagrama, Barcelona, 2019.

GARCÍA-ESCUDERO, P; "Parlamento y Gobierno en tiempos de multipartidismo", Corts: Anuario de derecho parlamentario, no 33, 2020.

GARCÍA FIGUEROA, A; "El convencionalismo jurídico o la irrelevancia del juspositivismo"; Persona y Derecho: Revista de fundamentación de las Instituciones Jurídicas y de Derechos Humanos, no 79, 2018.

GARCÍA FIGUEROA, A; "Neoconstitucionalismo y argumentación jurídica", Derecho PUCP: Revista de la Facultad de Derecho, no 79, 2017.

GARCÍA ROCA, J; La transformación constitucional del Convenio Europeo de Derechos Humanos, Aranzadi, Cizur Menor, 2019.

GARCÍA ROCA, J; "Los riesgos de una buena Constitución vieja: tiempos de reformas y democracia de consenso"; Revista de las Cortes Generales, no 106, 2019.

HÄBERLE, P; El Estado Constitucional, Instituto de Investigaciones Jurídicas-UNAM, México, 2011.

HAN, B-C; La sociedad del cansancio, Herder, Barcelona, 2012.

HIERRO, L; Los derechos humanos. Una concepción de la justicia, Marcial Pons, Madrid, 2016.

IGNATIEFF, M; Las virtudes cotidianas. Orden moral en un mundo dividido, Taurus, Madrid, 2018. 
KAISER, A; La neoinquisición. Persecución, censura y decadencia cultural en el siglo XXI, Deusto, Barcelona, 2020.

KEANE, J; Vida y muerte de la democracia, Fondo de Cultura Económica, Ciudad de Méjico, 2018.

KRIELE, M; Introducción a la teoría del Estado. Fundamentos históricos de la legitimidad del Estado constitucional democrático, Depalma, Buenos Aires, 1980.

LEYLAND, P; The Constitution of the United Kingdom: a contextual analysis, Hart Publishing, Oxford, 2007.

LÓPEZ GUERRA, L; La Constitución de España, Tirant lo Blanch, Valencia, 2019.

LOEWENSTEIN, K, Teoría de la Constitución, Ariel, Barcelona, 2018 (original de 1959).

MATIA PORTILLA, F.J; "Estado constitucional y democracia. Algunas consideraciones sobre la actual desafección hacia la clase política (ensayo)". En RUBIO LLORENTE, F; JIMÉNEZ CAMPO, J; SOLOZÁBAL ECHAVARRÍA, J.J; BIGLINO CAMPOS, P; GÓMEZ MONTORO, Á (coords). La Constitución Política de España: estudios en homenaje a Manuel Aragón Reyes, CEPC, Madrid, 2016.

MELERO DE LA TORRE, M; "Cultura constitucional". Eunomía. Revista en Cultura de la Legalidad, no 15, 2018-2019.

MOUNK, Y; El pueblo contra la democracia: porqué nuestra libertad está en peligro y cómo salvarla, Paidós, Barcelona, 2018.

MORENO CASTILLO, R; Breve tratado sobre la estupidez humana, Fórcola, Madrid, 2018.

MUÑOZ MACHADO, S; "Significado de la Constitución Española de 1978", En VVAA; Congreso Internacional Constitucional, CEPC, 2020, Madrid.

MURRAY, D; La masa enfurecida. Cómo las políticas de la identidad llevaron al mundo a la locura, Península, Barcelona, 2020.

OVEJERO, F; La deriva reaccionaria de la izquierda, Página Indómita, Barcelona, 2018.

PARDO, J.L, Estudios del malestar. Políticas de la autenticidad en las sociedades contemporáneas, Anagrama, Barcelona, 2016.

PEGORARO, L; "Constitucionalización del Derecho y cultura constitucional", Revista de Derecho Político, no 104, 2019.

PÉREZ DE LA FUENTE, Ó; "El caso de los tiradores del Muro de Berlín. A vueltas con algunos debates clásicos de la filosofía del derecho del siglo XX", Cuadernos Electrónicos de Filosofía del Derecho, no 23, 2011.

RUANO ESPINOSA, L; "Las Sentencias del Tribunal Supremo de 11 febrero 2009 sobre objeción de conciencia a EpC"; Revista General de Derecho Canónico y Derecho Eclesiástico del Estado, n० 20, 2009.

RUIZ-HUERTA CARBONELL, A; "La enseñanza de la Constitución en España: por una cultura constitucional"; Revista Jurídica de Castilla y León, nº extra 1, 2004. 
RUIZ MIGUEL, C; "El constitucionalismo cultural", Cuestiones Constitucionales, no 9, 2003.

RUNCIMAN, D; Así termina la democracia, Paidós, Barcelona, 2019.

SACHS, A; The Strange Alchemy Between Life and Law, Oxford University Press, Oxford, 2011.

SÁNCHEZ NAVARRO, Á; La transición española en sus documentos, CEPC, Madrid, 1998.

SARTORI, G; Elementos de Teoría Política, Alianza, Madrid, 2008, pássim.

SIEGEL, A.W; "Constitutional Theory, Constitutional Cultural", $18 \mathrm{U}$. Pa. J. Const. L. 1068 (2016)-Seattle University School of Law Research Paper, 2016.

TORRES MURO, I; "Constitución y Parlamento: notas para la comprensión de la institución parlamentaria en el siglo XXI", Revista de las Cortes Generales, no 87, 2012.

TUSHNET, M; Why the Constitution matters, Yale University Press, London-New Haven, 2010.

ZIBLATT, D; y LEVITSKY; S; Cómo mueren las democracias, Ariel, Barcelona, 2018.

VVAA; "El Tribunal Europeo de Derechos Humanos"; Teoría y Realidad Constitucional, n 42, 2018. 